\title{
The Role of Dietary Supplements in Depression and Anxiety - A Narrative Review
}

\author{
Authors \\ Knut Hoffmann1, 2, Barbara Emons², Stefan Brunnhuber ${ }^{3}$, Sedya Karaca², Georg Juckel1, 2
}

\author{
Affiliations \\ 1 LWL University Hospital for Psychiatry, Psychotherapy \\ and Preventive Medicine, Bochum, Germany \\ 2 LWL Institute for Mental Health, Bochum, Germany \\ 3 Diaconic Clinics Zschadrass, Colditz, Germany
}

Key words

supplements, depression, anxiety

$\begin{array}{ll}\text { received } & 07.11 .2018 \\ \text { revised } & 17.05 .2019 \\ \text { accepted } & 20.05 .2019\end{array}$

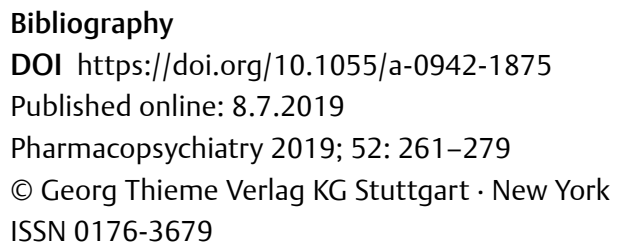

\section{Correspondence}

Knut Hoffmann

LWL-University Hospital for Psychiatry

Psychotherapy and Preventive Medicine, Alexandrinenstraße 1, 44791 Bochum, Germany knut.hoffmann@Iwl.org

\begin{abstract}
Introduction Dietary supplements are very widely used in the general population and there is a growing market for them, which is against the recommendations of the German Society for Nutrition. There is some evidence that dietary supplements are useful additions in the treatment of psychiatric disorders. This review is an overview of available practical knowledge regarding the use of supplements in psychiatric treatment. In particular, the review focused on the diagnosis of depression and anxiety in terms of supplement treatment.

Methods This is a narrative review of the evidence regarding supplements for treating anxiety and depression. We searched PubMed to 2018. Two reviewers screened the citations and abstracted the data. Phytopharmaceutical attends and animalbased data were excluded.

Results There are strong indications regarding the impact of supplements on the selected psychiatric disorders, but at this time, there only a few randomized clinical studies available, so evidence for these findings is quite low. However, it must be noted that there are strong hints for a relationship between vitamin $D$ level and depression. Furthermore, various supplements have got potentially an influence on the characteristics of depression.

Discussion This review summarizes the current knowledge about supplements when used for some psychiatric conditions, but the data does not provide compelling evidence in any direction. There are only indications that there is an influence of supplements on psychiatric diseases. In support of this, there is further need for high-quality studies in this field. Reviews on other diagnoses, such as schizophrenia and dementia, will be part of further work.
\end{abstract}

\section{Introduction}

According to European and German law, dietary supplements are defined as chemical substances like minerals, vitamins, and antioxidants, which are part of normal nutrition but also can added to normal nutrition in the shape of more or less pure substances. Vitaminoids such as coenzyme Q10, carnitine, and inositol are also subsumed under the group of dietary supplements. In Germany, there is also a special regulation called the Dietary Supplement Act (Nahrungsergänzungsmittelverordnung, NemV). According to the recommendations of the German Society for Nutrition, and also the German Federal Institute for Risk Rating (Bundesinstitut für Risikobewertung, BfR), dietary supplements are not necessary for healthy persons who have a normal nutritional intake [1]. Despite this, there is a huge industry supplying the population with these products and a sales volume of $\$ 1.2$ billion USD a year [2,3], and this does not include sales from supermarkets. These products are usually used without any medical consultation, and advertisement in newspapers, TV, or other media is legal in opposition to genuine pharmaceutical drugs. Magnesium is one of the most popular dietary supplements, followed by calcium and iron, and vitamin A, $D$, and $B$ formulations are increasing at the highest rates the in Germany [2]. It is also well known that although the fat-soluble vitamins (vitamin $A$, vitamin $D$, vitamin $E$, and vitamin $K$ ) can possibly enrich in the fatty tissues of the human being, overdoses and in- 
toxications of vitamin A have been reported sporadically. In general reports of adverse effects and poisoning due to consuming dietary supplements are increasing [4,5].

Despite this nonmedical application of dietary supplements they are also used for specific medical conditions. Deficiencies in vitamins and minerals may be caused by special forms of diet, such as a strict vegetarian or vegan diet. These deficiencies can lead to specific medical conditions that can be identified via blood tests or may lead to distinct neurological or hematological symptoms. A Cochrane review in 2012 involved a meta-analysis of 78 clinical studies with nearly 300000 probands and found that the continuous supplementation of antioxidants such as beta carotene, vitamin $E$, and probably vitamin A has raised mortality significantly with a relative risk of $1.0006, p=0.002$ [6].

There are also psychiatric conditions that are sometimes treated with dietary supplements. The most common are depression and anxiety disorders. There are a few hospitals in Germany that have added treatment with dietary supplements routinely to classical psychopharmacological and psychotherapeutic treatment in their therapeutic repertoire. The core aim of this study is to reveal the possible evidence of such substances in the treatment of depression and anxiety. The selection of the search topics was carried out after a primarily, not systematic, informative search in PubMed these topics where the only once with an expected big enough outcome.

\section{Methods}

A narrative review on the effect of supplements on different psychiatric disorders is provided, which explicitly does not match the criteria of a meta-analysis. The included studies were found via PubMed.

\section{Search strategy}

We searched the electronic databases PubMed without language restriction from January 2012 to April 2018 to identify effect of supplements on different psychiatric disorders. Our search was limited to peer-reviewed literature.

\section{Eligibility criteria}

The inclusion and exclusion criteria for this narrative review were developed using the frame of participants, kind of supplement, and psychiatric diagnosis.

\section{Participants}

Studies in adults, male and female, with a psychiatric diagnosis.

\section{Supplement}

Studies on the supplements vitamin $D(V i t D)$, polyunsaturated fatty acids (PUFA), vitamin C, N-acetylcysteine (NAC), inositol, folic acid, and citicholine were selected.

\section{Psychiatric diagnosis}

Psychiatric diagnosis depression and anxiety were selected. Also, therapeutic aspects have been used for selection in case of depression.

\section{Search terms}

The search was conducted on a combination of the supplement and psychiatric diagnosis of interest. Also, the search was conducted in an open manner with view of supplements in general.

\section{Data extraction}

Data from selected studies were extracted in tabular form including the basic information on the study, study design, study time, supplements, psychiatric diagnosis, participants, results, and limitations.

\section{Descriptive analysis}

Descriptive analysis was based on the summary of the effects of supplements on the selected psychiatric diagnosis.

\section{Results}

The effects of dietary supplement will be sorted by diagnosis below.

\section{The role of supplements in depressive disorder}

Most studies used in this review refer to depressive disorder. The findings of these studies are summarized in $\triangleright$ Tables $\mathbf{1}$ and $\boldsymbol{2}$. The studies are divided into 2 approaches: those referring to diagnostic approaches to supplements and those referring to therapeutical approaches. The diagnostic approaches are summarised in - Table 1

Vid $\mathrm{D}$ and depressive disorder

Many studies refer to reduced Vit D serum levels in populations suffering from depressive disorder [8-16]. Belzeaux et al. found that hypovitaminosis of Vit D was generally more severe in patients with depression than patients with schizophrenia [7]. Furthermore, a positive association between anhedonia and low Vit D [17] was found, and significant reduction in cognitive functioning in people suffering from MDE associated with lower Vit D levels were reported [18]. Lee at al. refers to a cross-dependency between Vit D levels and serum cholesterol [19]. Brouwer-Brolsma et al. [20] used data from the B-PROOF study $(n=2839$, age $65+)$ and found that long-term Vit $D$ substitution had a significant effect on depressive symptoms, but there could be no interaction with Vit D regulating genes found in elderly people with elevated homocysteine levels. Pregnant Afro-American women aged 18-44 seemed to have a higher risk of postpartum depression relating to low Vit D levels in the second trimester, and there was also lower inflammatory cytokine activity [21]. Johansson et al. [22] found a positive relationship between reduced Vit $D$ levels and depression in 506 patients with chronic heart disease. BDI-II scores in 126 patients with stroke were significantly negatively correlated with low Vit D levels, but not PHQ-9 scores [23]. Rabenberg et al. [24] stated that the higher association of Vit D deficiency and depression during summertime in a sample of 6331 participants may be a consequence and not a cause of depression. Kerr et al. [25] investigated Vit D levels in relation to light exposure (measurement over autumn, winter, and spring) and found that the incidence of depression was higher with low Vit D levels independent of season. Elstgeest et al. [26] could demonstrate that over a period of 6 years, natural changes in Vit D 


\begin{tabular}{|c|c|c|c|c|c|c|c|}
\hline & 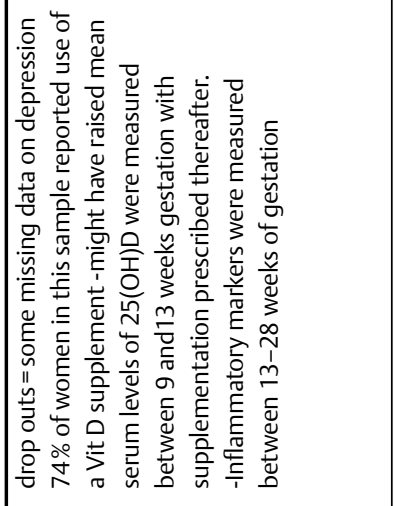 & 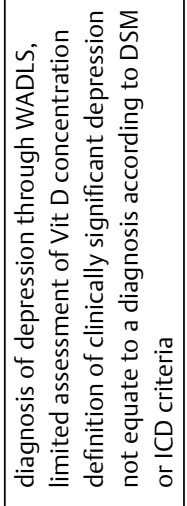 & 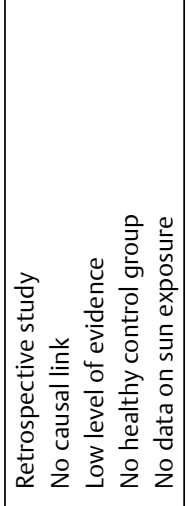 & 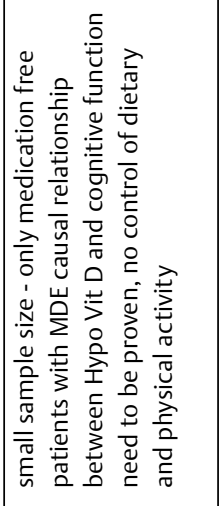 & 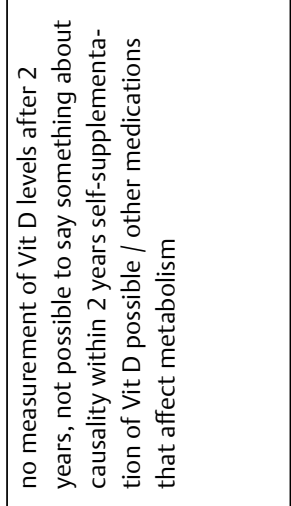 & 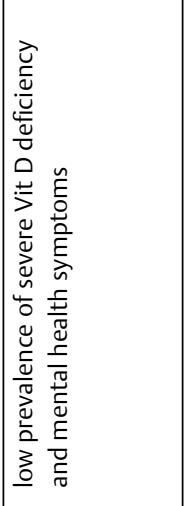 & 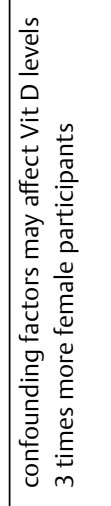 \\
\hline 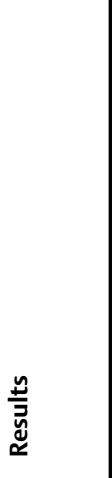 & 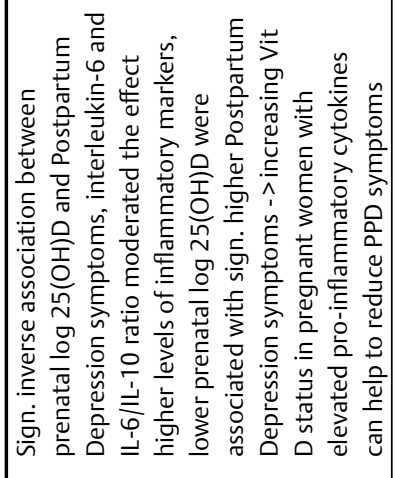 & 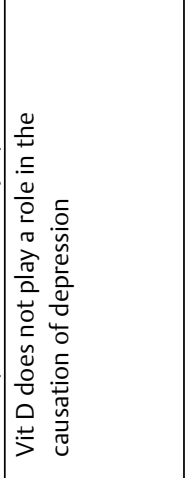 & 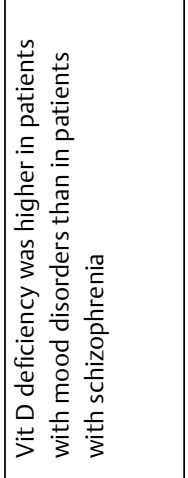 & 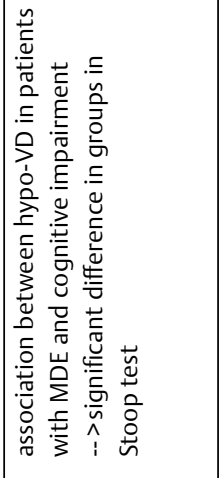 & 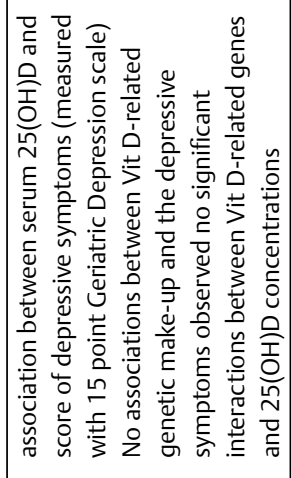 & 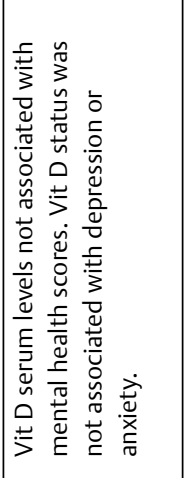 & 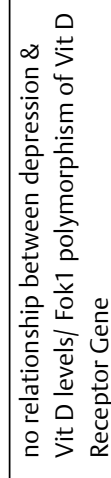 \\
\hline$\frac{5}{\bar{y}}$ & 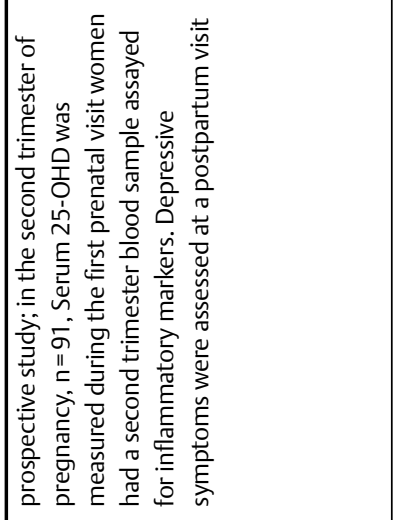 & 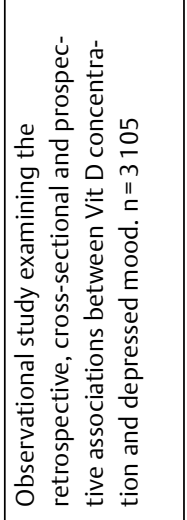 & 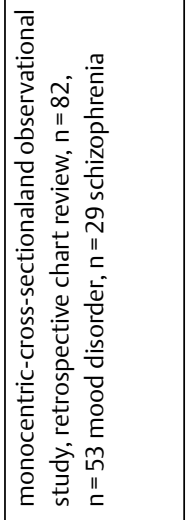 & 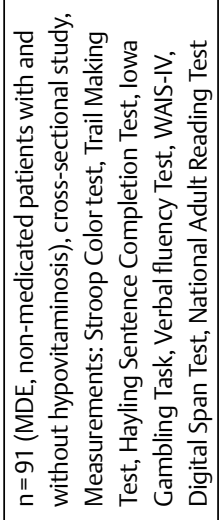 & 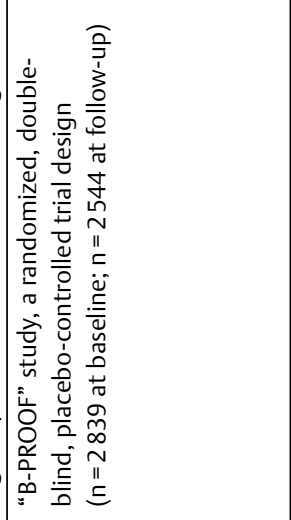 & 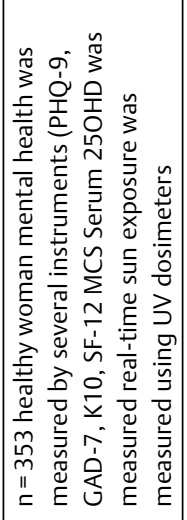 & 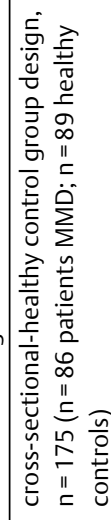 \\
\hline & $\begin{array}{l}0 \\
\stackrel{5}{*}\end{array}$ & $\stackrel{0}{\stackrel{0}{*}}$ & 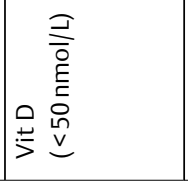 & 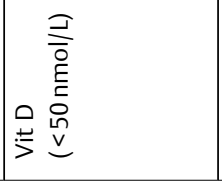 & $\stackrel{0}{\overrightarrow{5}}$ & $\stackrel{\circ}{\stackrel{2}{5}}$ & $\begin{array}{l}0 \\
\dot{3}\end{array}$ \\
\hline & 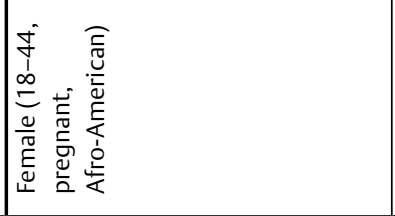 & 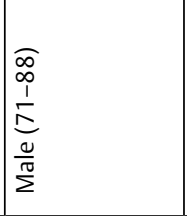 & $\frac{y}{\frac{y}{2}}$ & 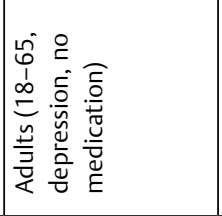 & 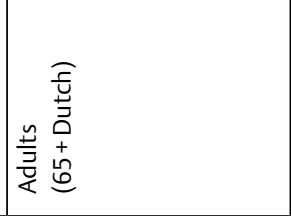 & 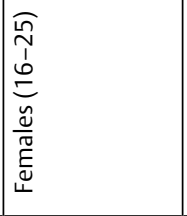 & 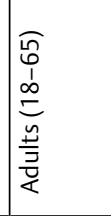 \\
\hline 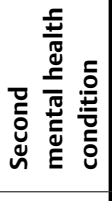 & & & 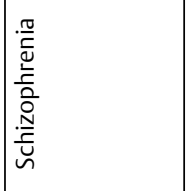 & 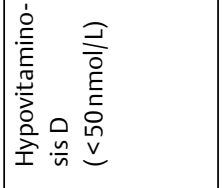 & & $\mid \frac{\overrightarrow{0}}{\frac{0}{x}}$ & \\
\hline 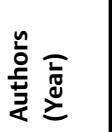 & 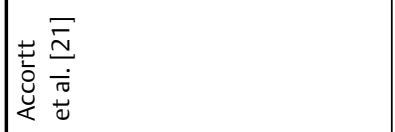 & 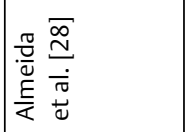 & 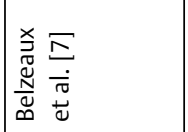 & 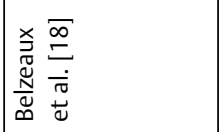 & 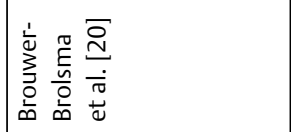 & 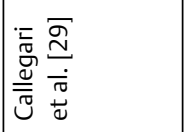 & 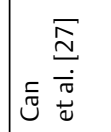 \\
\hline
\end{tabular}




\begin{tabular}{|c|c|c|c|c|c|c|c|}
\hline & 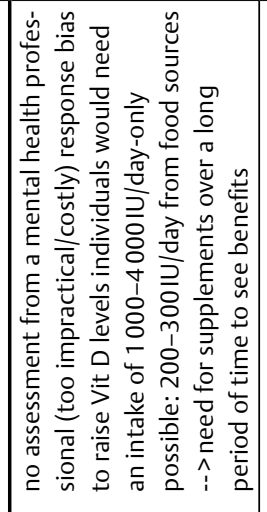 & 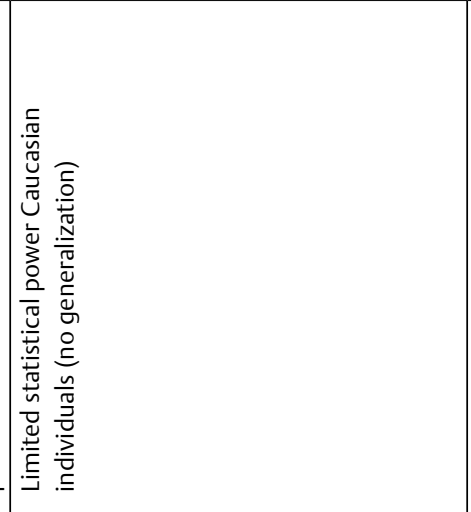 & & 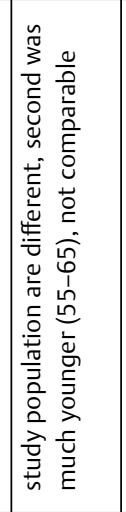 & 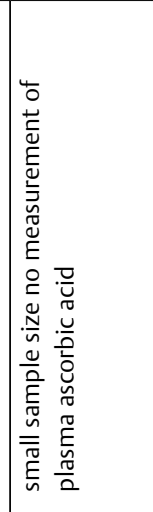 & 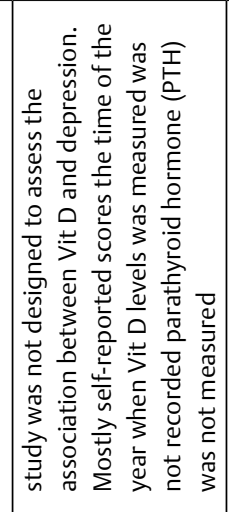 & 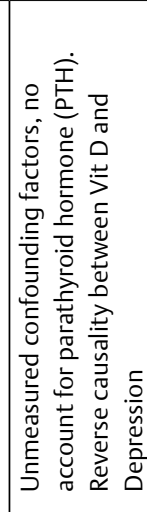 \\
\hline 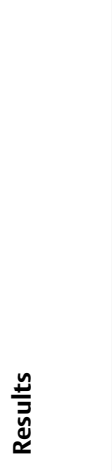 & 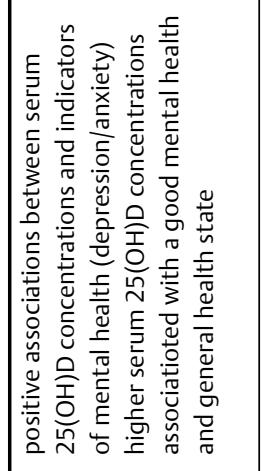 & 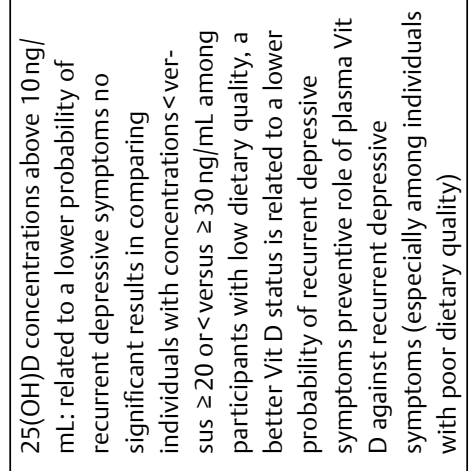 & 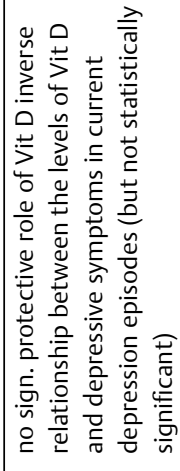 & 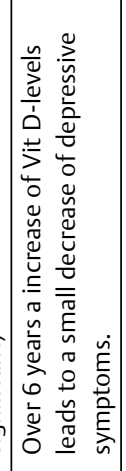 & 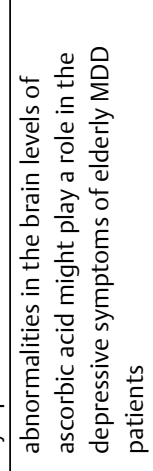 & 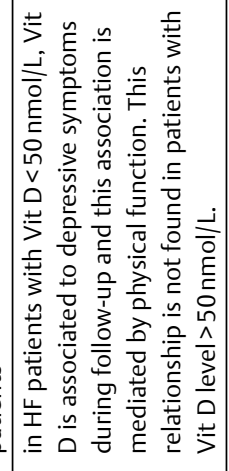 & 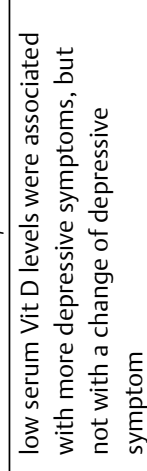 \\
\hline 志 & 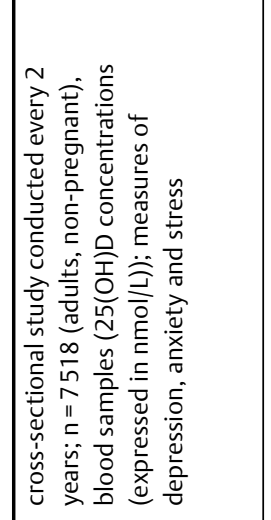 & 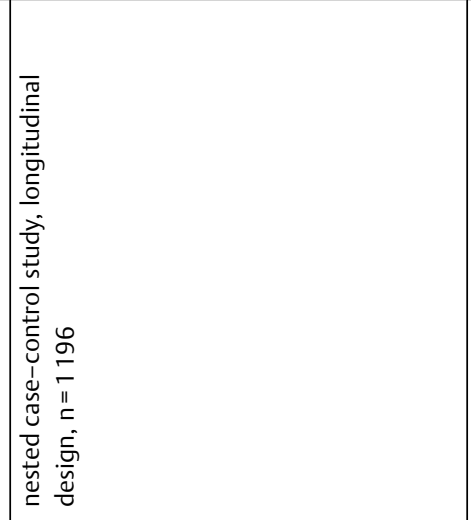 & 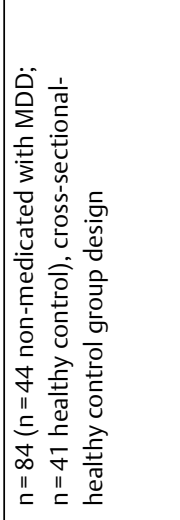 & 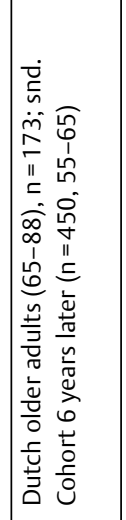 & 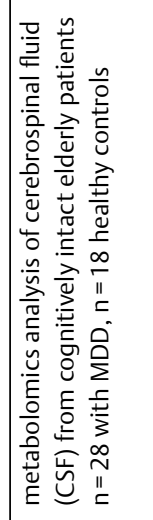 & 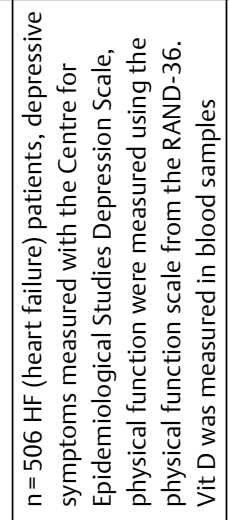 & 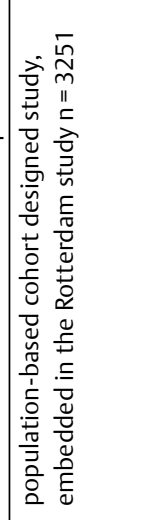 \\
\hline & $\stackrel{0}{\stackrel{0}{*}}$ & $\stackrel{\circ}{\stackrel{0}{\lessgtr}}$ & $\begin{array}{l}0 \\
\dot{5}\end{array}$ & 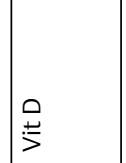 & $\begin{array}{l}\dot{U} \\
\dot{>}\end{array}$ & $\begin{array}{l}0 \\
\stackrel{0}{*}\end{array}$ & $\stackrel{0}{\stackrel{0}{*}}$ \\
\hline & 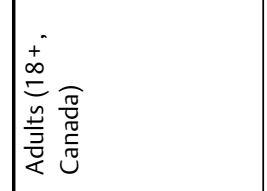 & $\frac{\frac{n}{3}}{\frac{\pi}{\alpha}}$ & 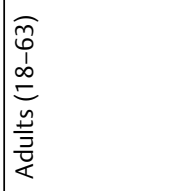 & & 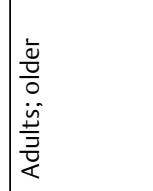 & 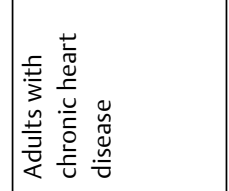 & 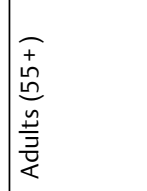 \\
\hline 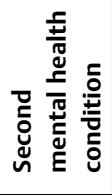 & 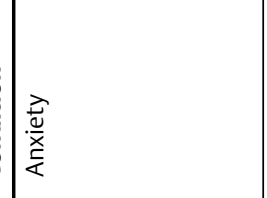 & & & & & 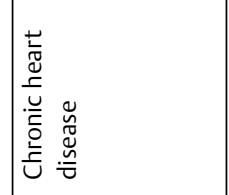 & \\
\hline 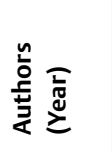 & 론 $\frac{\infty}{\frac{\infty}{\pi}}$ & 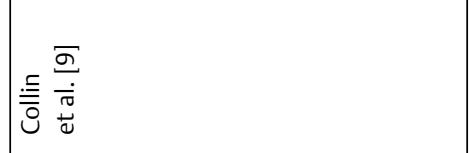 & 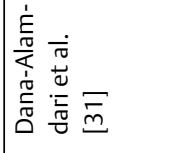 & 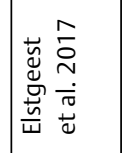 & 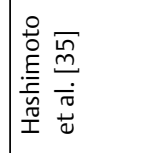 & 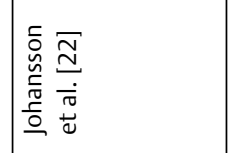 & 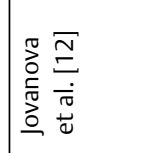 \\
\hline
\end{tabular}




\begin{tabular}{|c|c|c|c|c|c|}
\hline & & 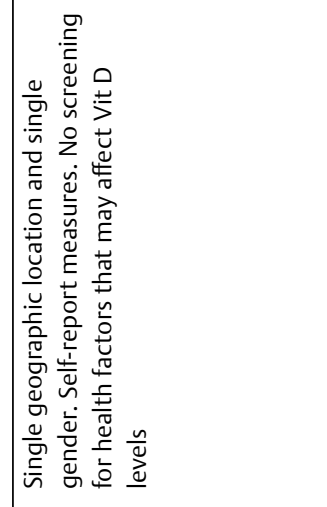 & & 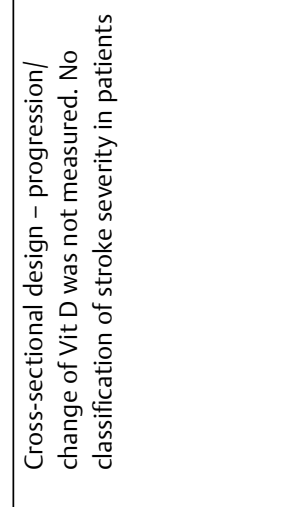 & 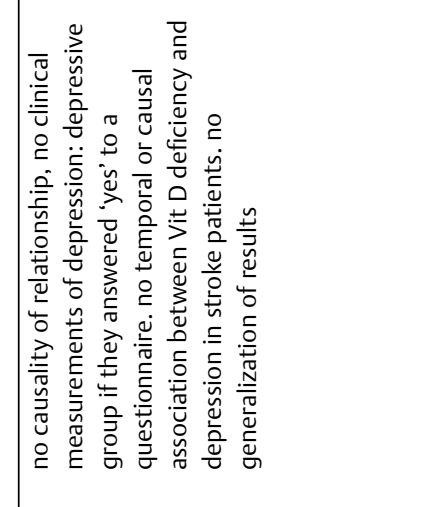 \\
\hline$\frac{\underline{y}}{\bar{z}}$ & 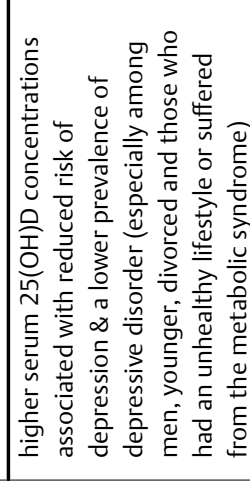 & 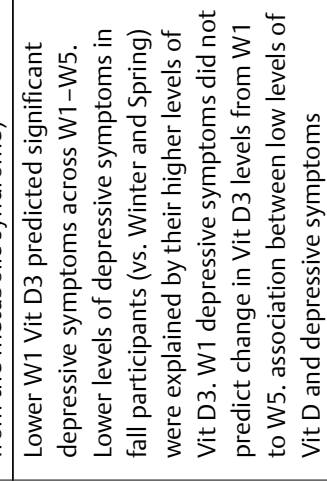 & 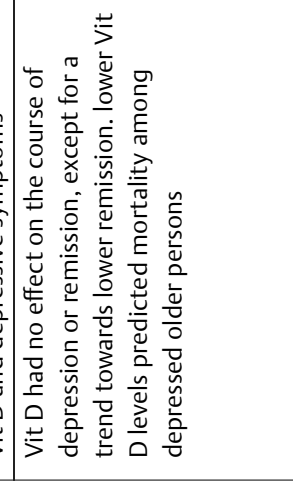 & 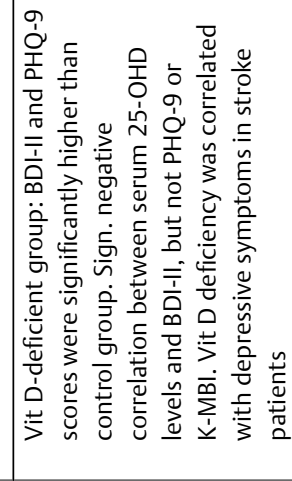 & 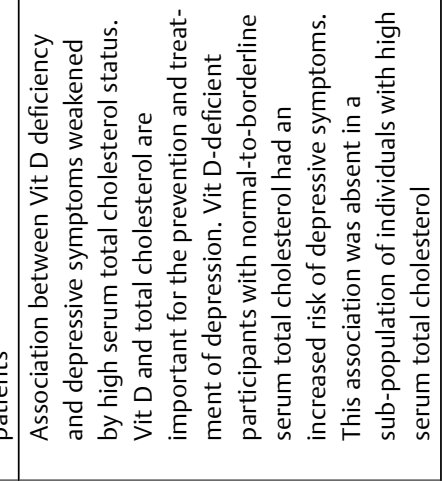 \\
\hline 点 & 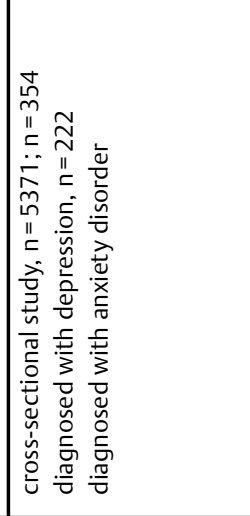 & 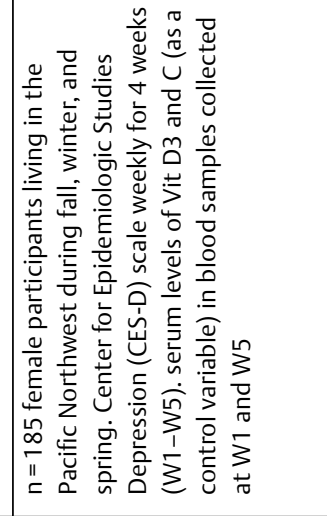 & 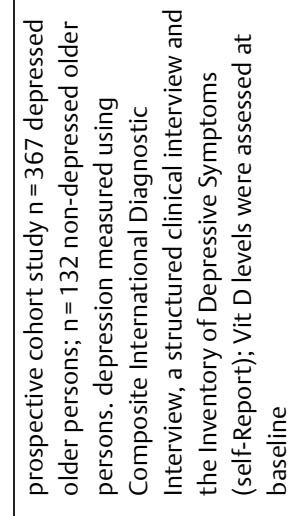 & 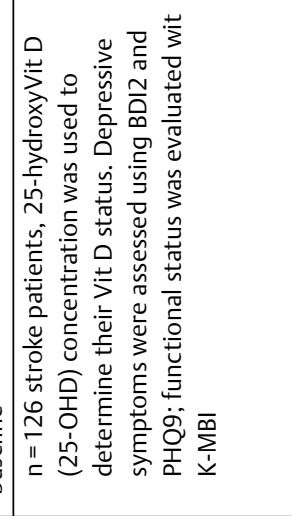 & 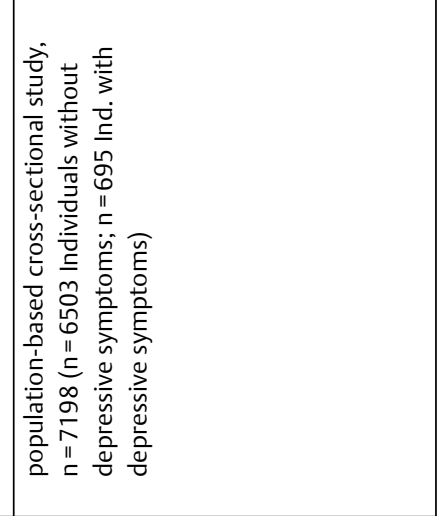 \\
\hline & $\stackrel{p}{\lessgtr}$ & $\stackrel{P}{\stackrel{p}{>}}$ & $\stackrel{0}{\vec{y}}$ & 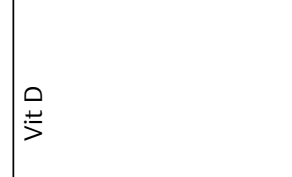 & $\mid \vec{p}$ \\
\hline & 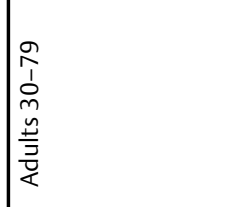 & 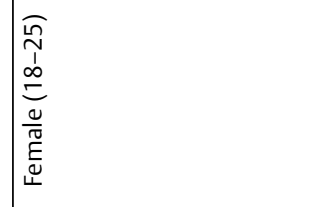 & $\mid \begin{array}{l}+ \\
0 \\
0 \\
\frac{n}{\bar{z}} \\
\frac{z}{4}\end{array}$ & 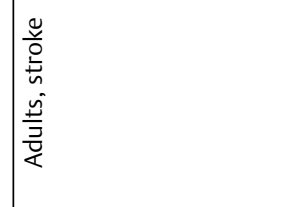 & 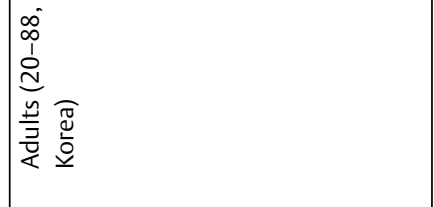 \\
\hline 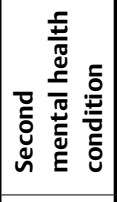 & & & & 总 & \\
\hline 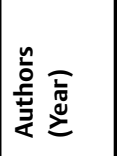 & 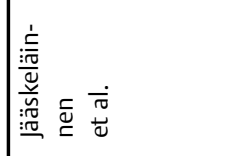 & 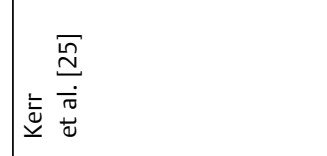 & 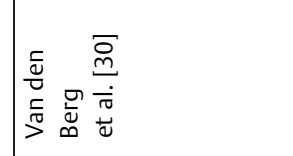 & 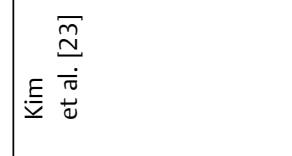 & 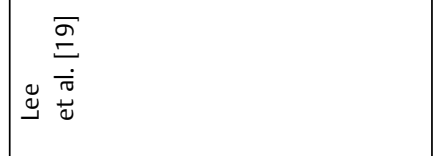 \\
\hline
\end{tabular}




\begin{tabular}{|c|c|c|c|c|c|c|c|}
\hline & 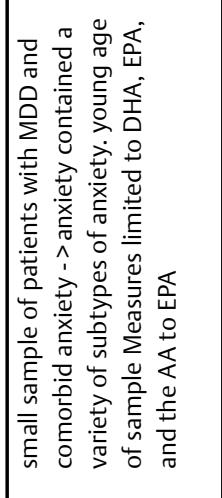 & 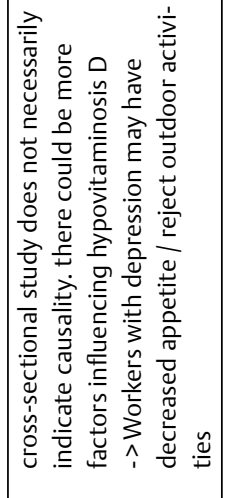 & 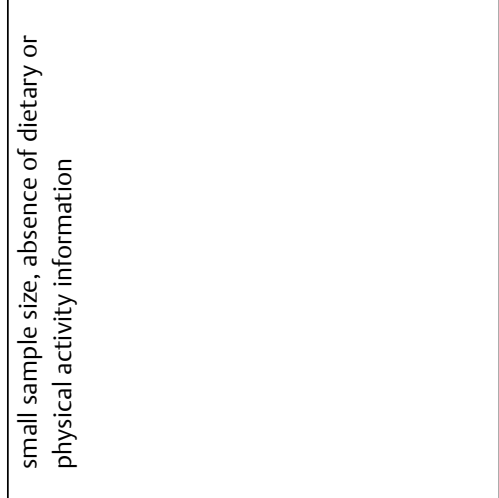 & & 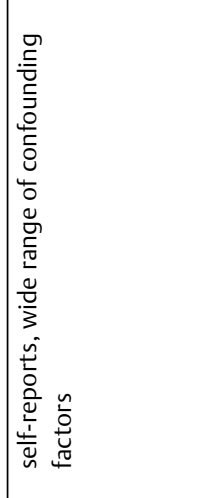 & & 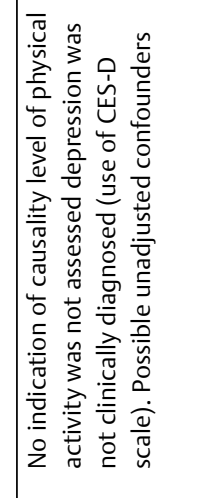 \\
\hline$\frac{n}{\vec{y}}$ & 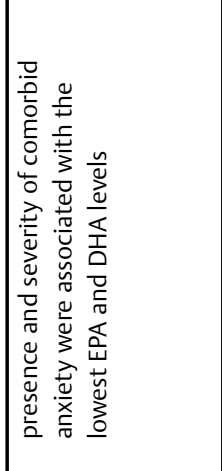 & 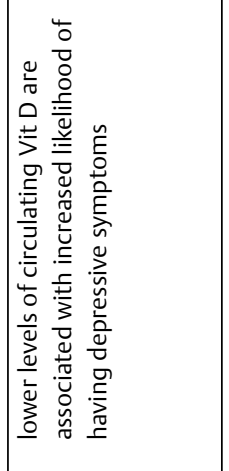 & 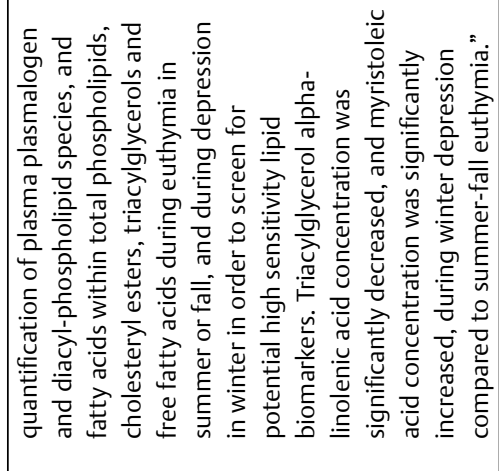 & & 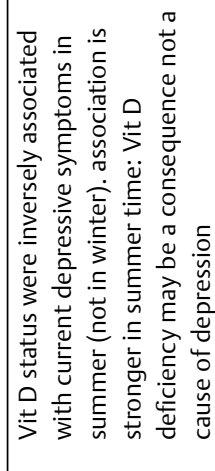 & 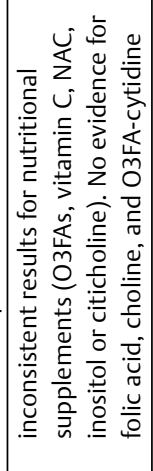 & 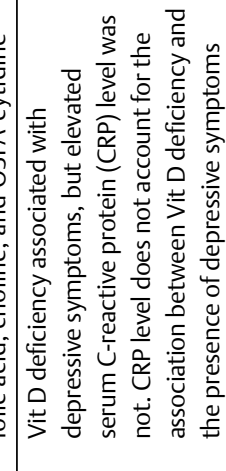 \\
\hline & 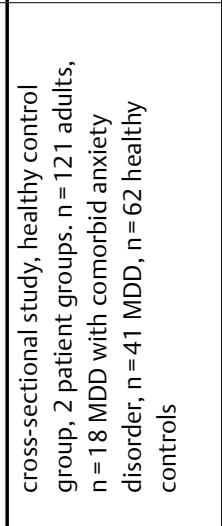 & 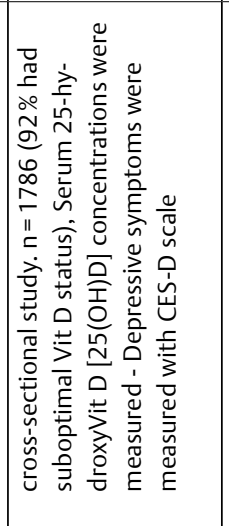 & 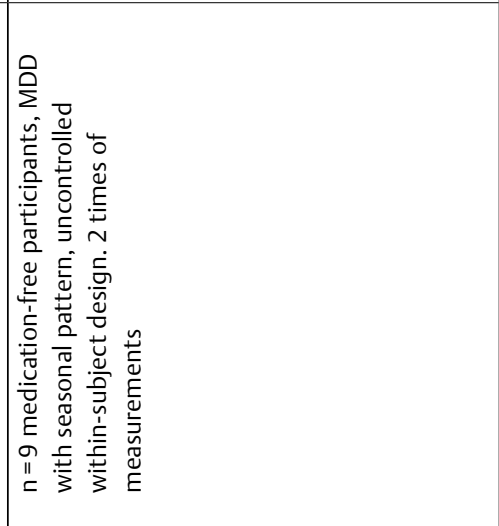 & & 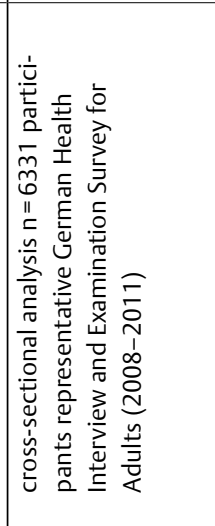 & 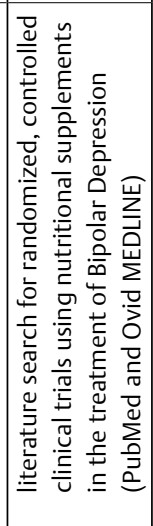 & 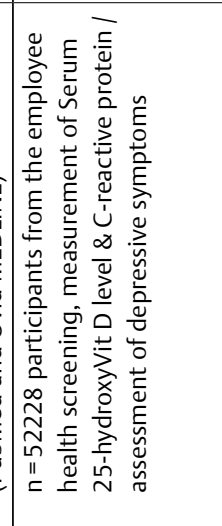 \\
\hline & 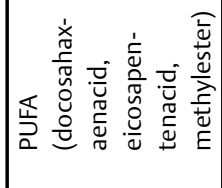 & & 总 & & $\stackrel{0}{\stackrel{2}{5}}$ & & $\stackrel{0}{\stackrel{0}{*}}$ \\
\hline & 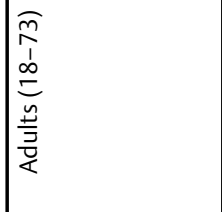 & 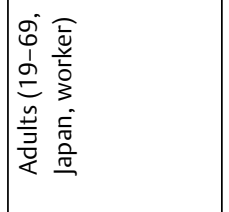 & 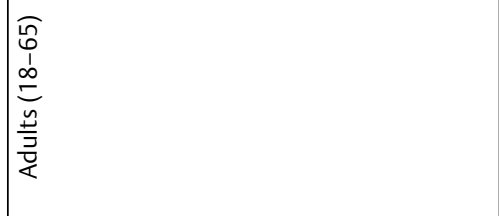 & & 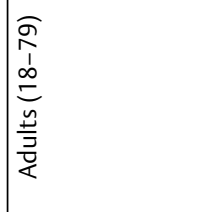 & & 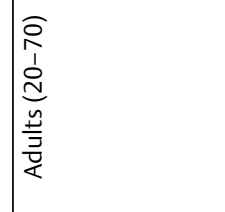 \\
\hline 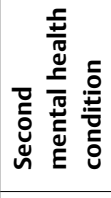 & $\underset{\overrightarrow{\vec{u}}}{\vec{x}}$ & & & & & & \\
\hline 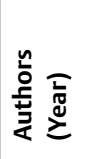 & 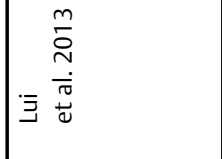 & 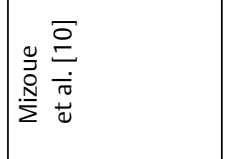 & $\frac{\bar{m}}{\frac{m}{\tilde{m}}}$ & 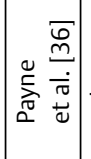 & 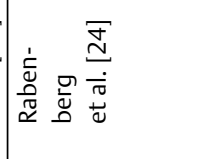 & 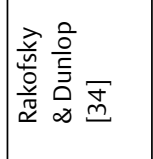 & 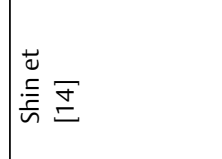 \\
\hline
\end{tabular}




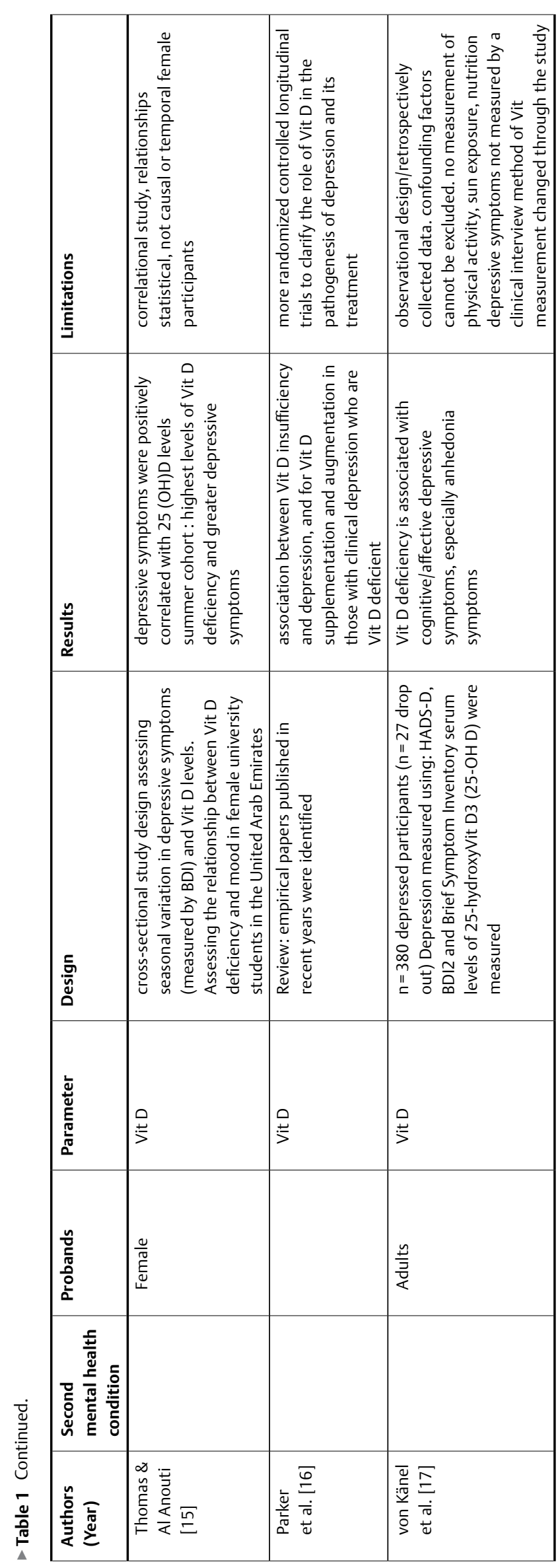

levels were related to depressive symptoms, independent of the age of the patient. Other studies did not find a relationship between Vit $D$ and affective disorder [27-30] or any protective effect of Vit D on depression [31]. In summary, it can be emphasized that there are reduced Vit D levels in populations suffering from depressive disorders [8-16, 21-23]. Further, many studies indicate that Vit D levels refer to depressive symptoms and their incidence [24-26], but also there are studies that did not find any relationship between depression an Vit D levels [27-30].

The role of PUFA, Vit C, NAC, inositol, folic acid, and citicholine in affective disorders

The effect of PUFA on depression was also investigated. Low levels of PUFA were associated with higher levels of both depression and anxiety [32,33]. Both studies refer only to small sample sizes. Rakofsky et al. undertook a literature search on PUFA, Vit C, NAC, inositol, folic acid, and citicholine and found inconsistent correlation between PUFA, Vit C, and citicholin and bipolar disorder, no correlation between folic acid, choline and cytidine-PUFA and bipolar disorder [34]. Hashimoto et al. also found significantly $(p=0.0029)$ higher levels of Vit C in the cerebrospinal fluid CSF of elderly people with depression, but no cognitive decline in comparison with healthy controls [35]. The elevation was interpreted as a result of increased oxidative stress in the central nervous system. Payne et al. studies the nutrition habits of depressed people with a lower intake of fruits and vegetables, resulting in lower Vit C levels. In this study, natural Vit C intake seems to be beneficial for depression, but Vit C from dietary supplements has no effect [36]. This implicates that various supplements have influence on depression or being influenced by depression [32-36].

\section{Supplements and therapeutical approaches}

Therapeutical approaches are summarized in > Table 2.

Vit D

Again, most of the literature refers to $V i t D$, and the findings regarding therapeutical aspects are also contradictory. A possible positive effect was found in a review by Mulcahy et al., but it was also noted that depression-associated behavior (e. g., social withdrawal, diminished cognitive capacity) may lead to poor diet and the measured effects are not caused by influencing depression, but depression-associated behavior [37]. Stokes et al. [38] investigated 278 patients with chronic liver disease (144: MDD, 134: no MDD) and found a significant improvement in depressive symptoms in a group supplemented with 20000 UI Vit D per week [38], and there was a similar finding by Penkhofer et al. in 82 depressive females with comorbid DM II 50000 IU/week) [39]. Gowda et al. undertook a meta-analysis of RCTs in this field $(n=4923)$ and found no significant effect in the reduction of depressive symptoms: most studies focused on mild depressive disorders [40]. Muosa et al. conducted an RCT of Vit D vs. placebo ( $n=33$ vs. 17 ) and found no effect on depression and anxiety in both arms [41], and a very similar study design with comparable findings was used by Marsh et al. [42] and Kjaegaard et al. [43]. In a supplementation-study (50 $000 \mathrm{lU} /$ week), Sephermanesh et al. (2016) only found a trend in reduction of BDI scores [44]. In a randomized pilot study, Rolf et al. treated 20 patients suffering from MS with $14000 \mathrm{IU}$ Vit D/d, controlled by 


\begin{tabular}{|c|c|c|c|c|c|c|}
\hline & 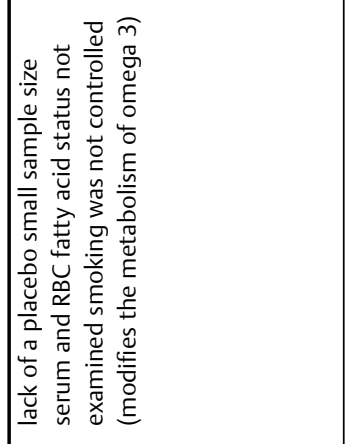 & 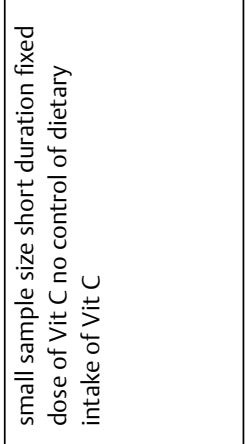 & 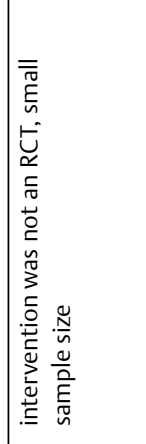 & 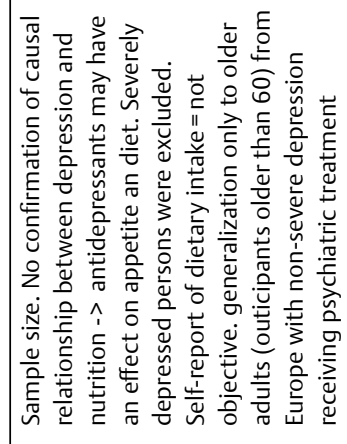 & 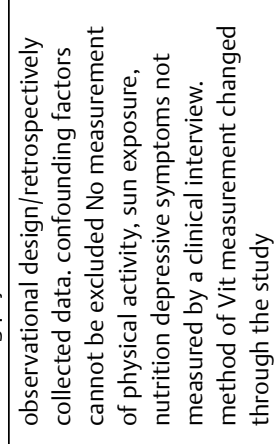 & 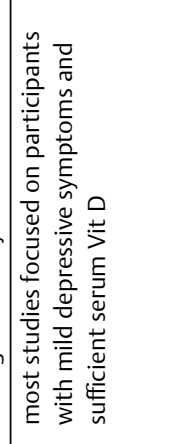 \\
\hline 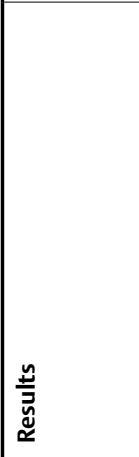 & 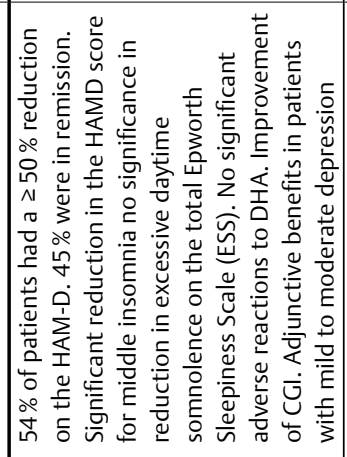 & 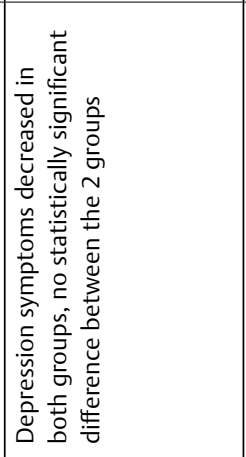 & 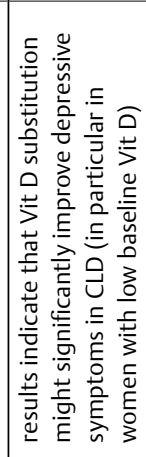 & 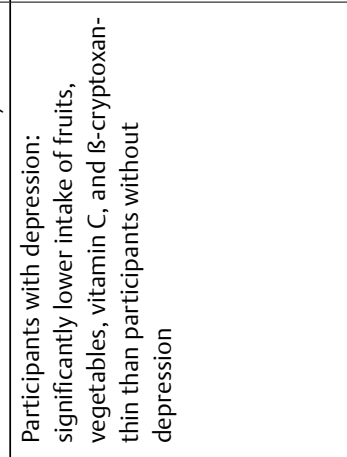 & 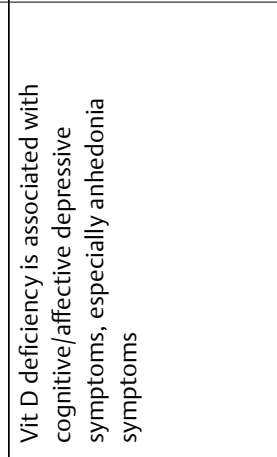 & 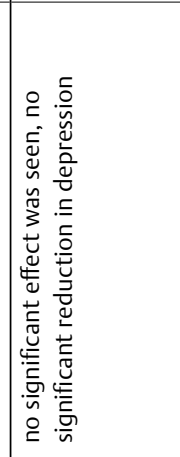 \\
\hline $\begin{array}{l}. \overline{5} \\
\bar{y}\end{array}$ & 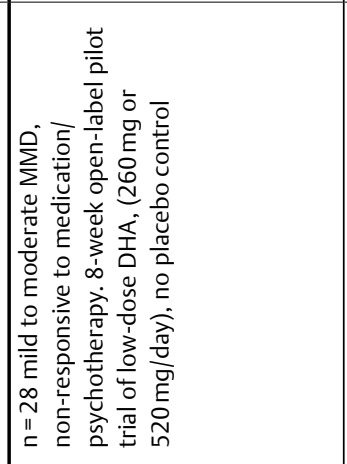 & 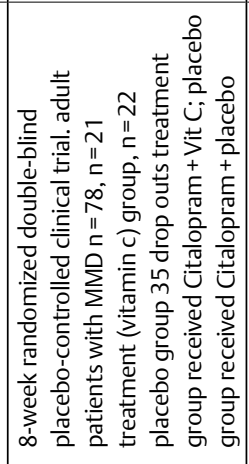 & 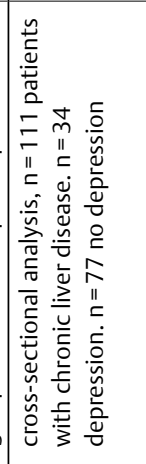 & 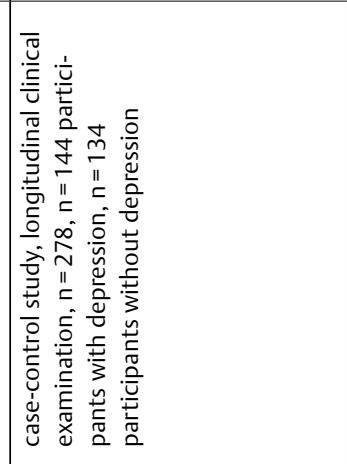 & 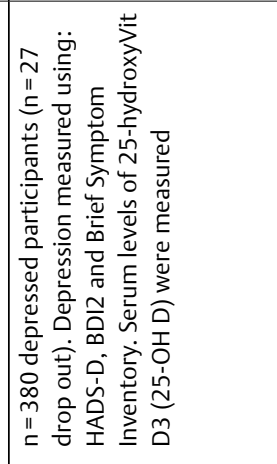 & 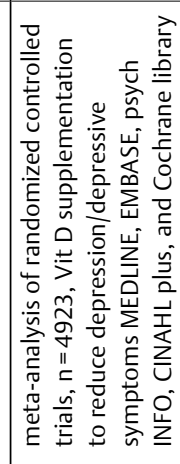 \\
\hline 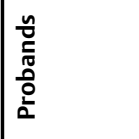 & $\frac{n}{\frac{y}{3}}$ & $\frac{\frac{n}{3}}{\frac{3}{4}}$ & $\frac{y}{\frac{y}{5}}$ & $\frac{n}{\frac{y}{2}}$ & $\frac{y}{\frac{y}{z}}$ & $\frac{\frac{n}{3}}{\frac{\pi}{x}}$ \\
\hline 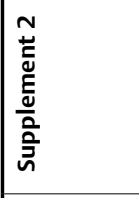 & & & & 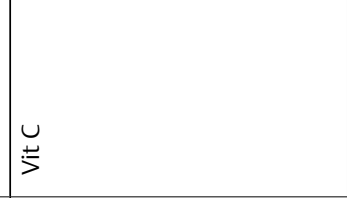 & & \\
\hline 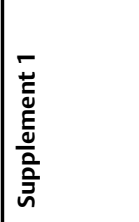 & 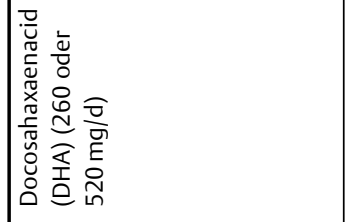 & 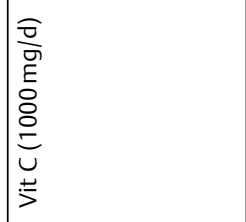 & 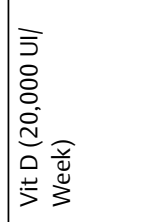 & 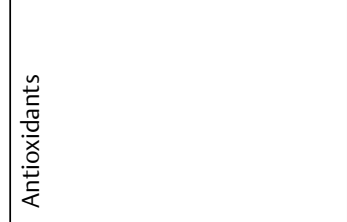 & & $\stackrel{0}{\stackrel{0}{>}}$ \\
\hline ن & & 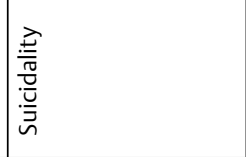 & 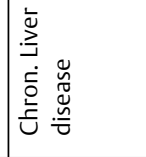 & & & \\
\hline 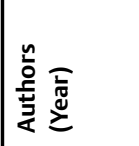 & 位 & 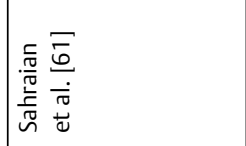 & 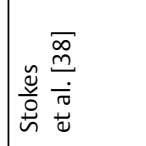 & 竞 & 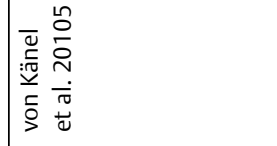 & 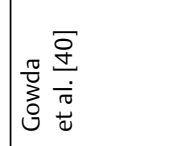 \\
\hline
\end{tabular}




\begin{tabular}{|c|c|c|c|c|c|c|}
\hline & 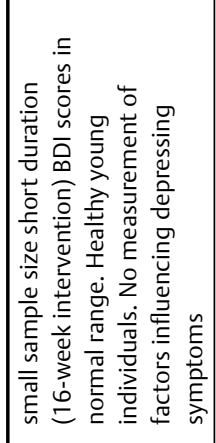 & 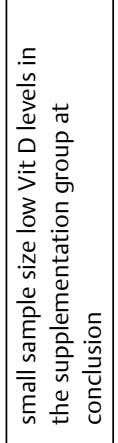 & 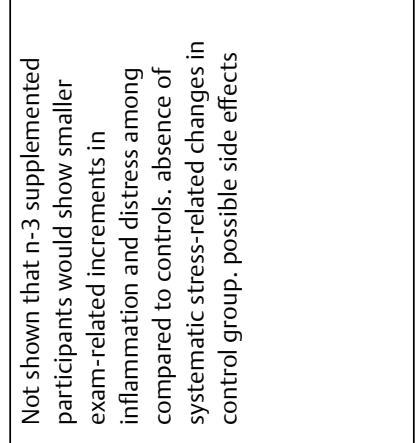 & 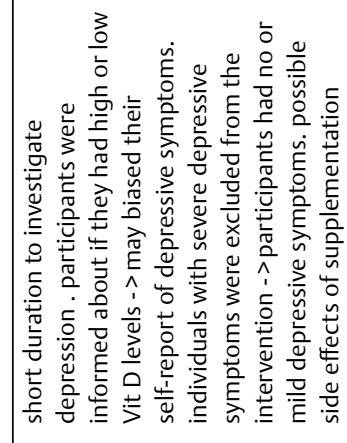 & 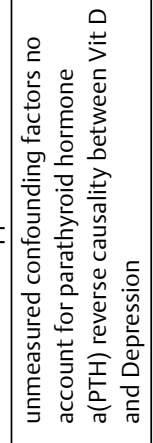 & 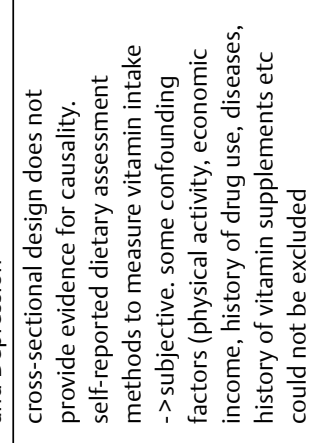 \\
\hline 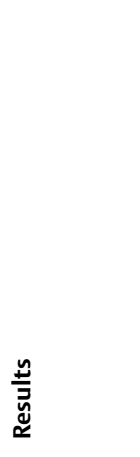 & 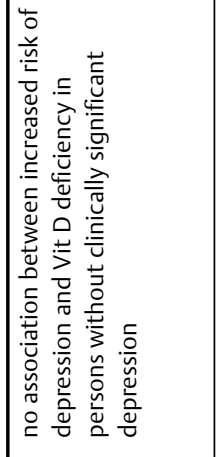 & 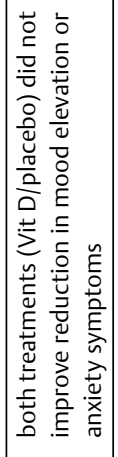 & 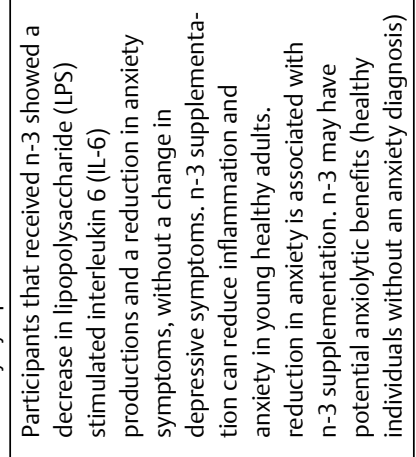 & 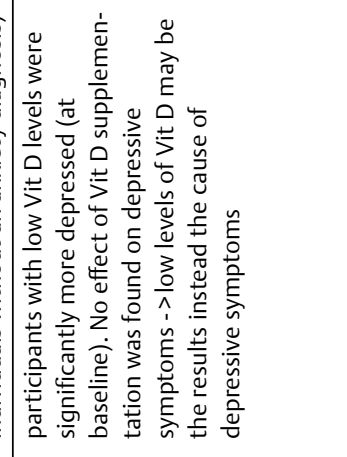 & 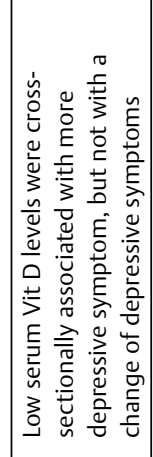 & 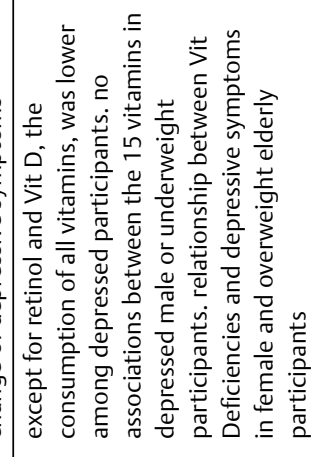 \\
\hline 鴶 & 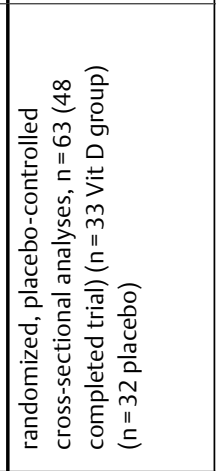 & 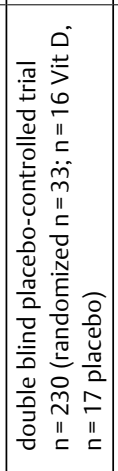 & 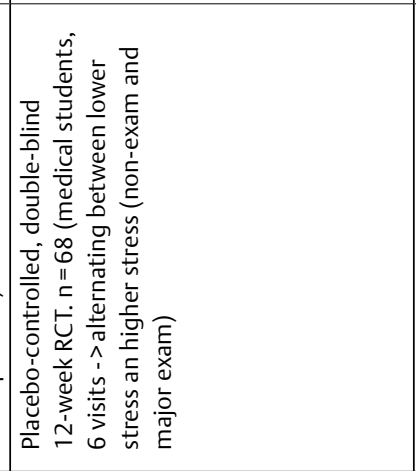 & 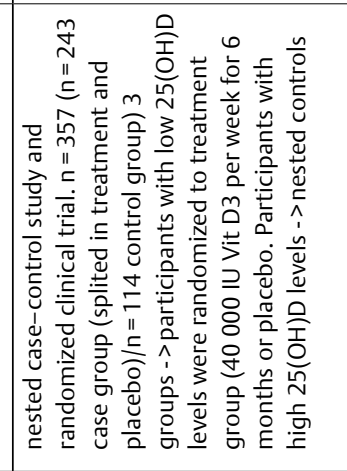 & 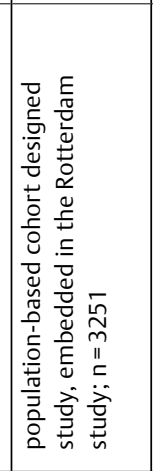 & 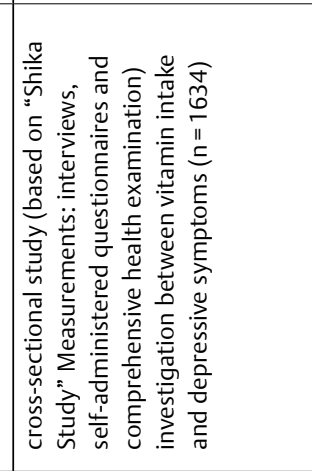 \\
\hline & 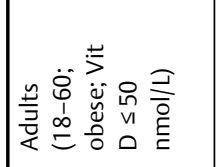 & 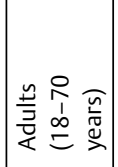 & 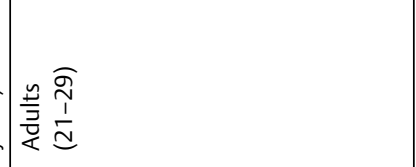 & 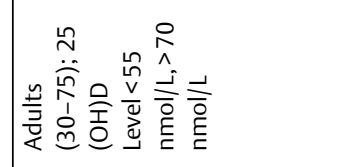 & 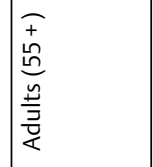 & 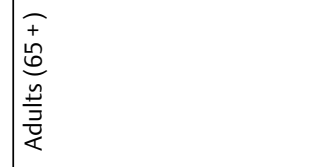 \\
\hline & & & & & & 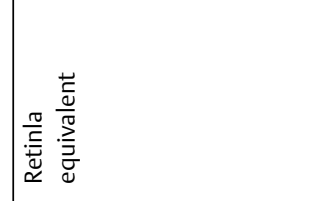 \\
\hline & 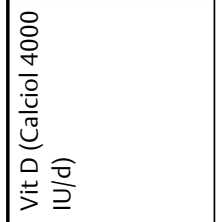 & 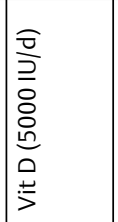 & 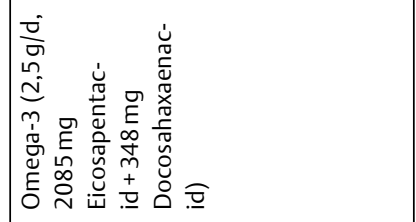 & 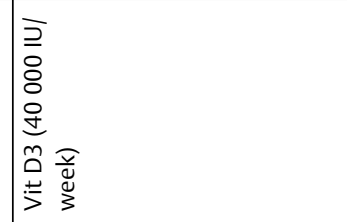 & & 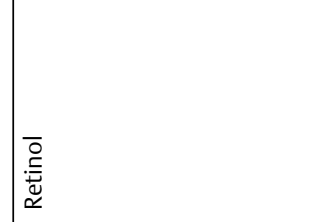 \\
\hline 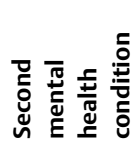 & & & 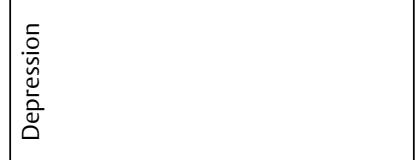 & & & \\
\hline 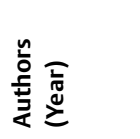 & 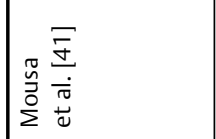 & 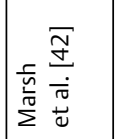 & 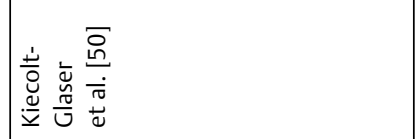 & 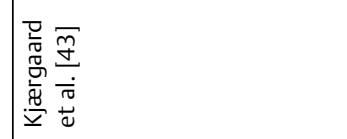 & 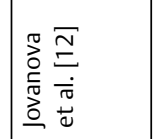 & 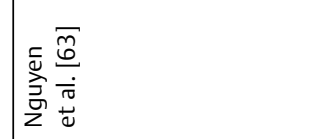 \\
\hline
\end{tabular}




\begin{tabular}{|c|c|c|c|c|c|c|}
\hline & 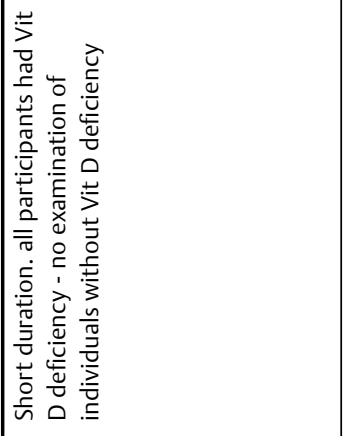 & & 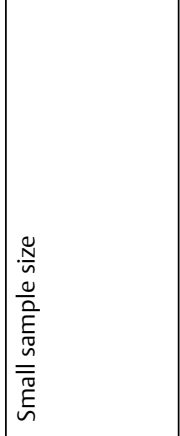 & 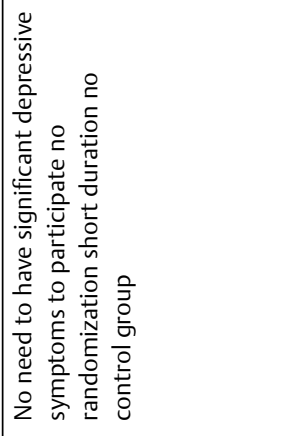 & 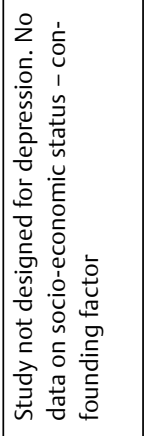 & 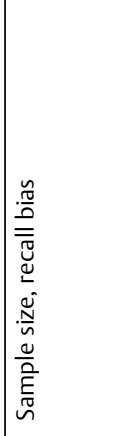 \\
\hline 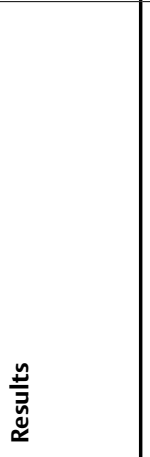 & 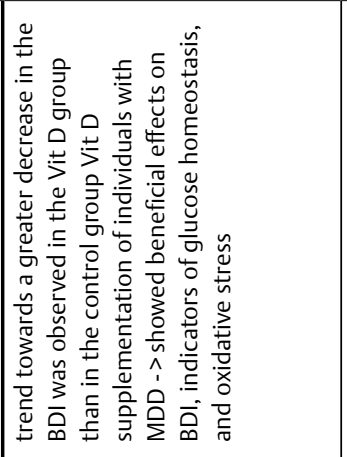 & 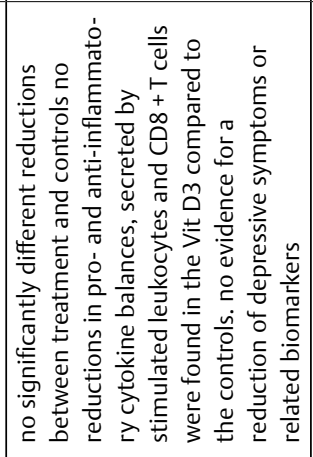 & 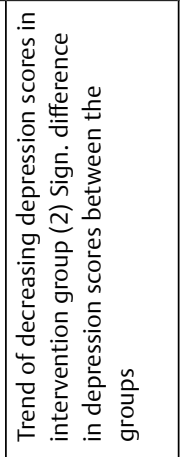 & 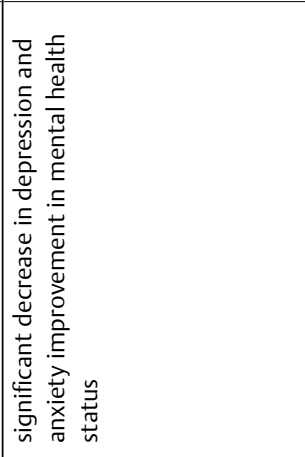 & 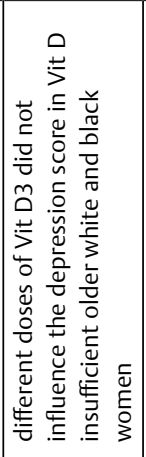 & 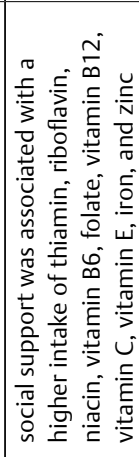 \\
\hline 鴶 & 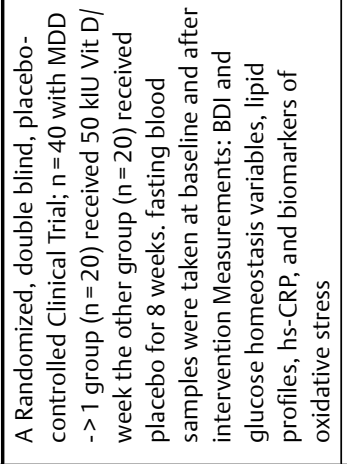 & 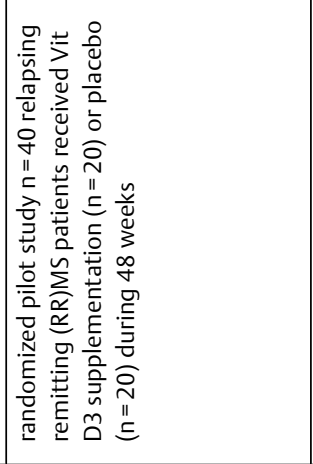 & 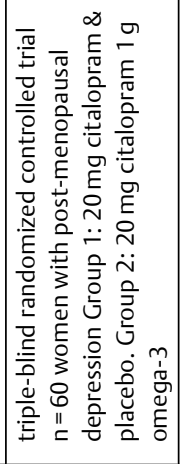 & 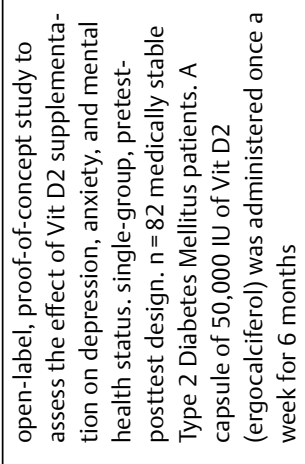 & 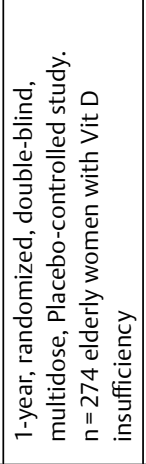 & 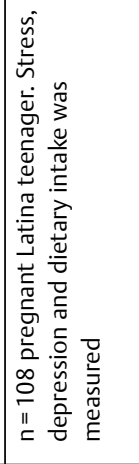 \\
\hline & 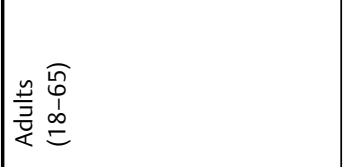 & 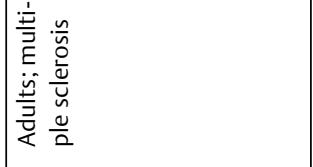 & 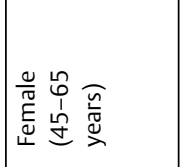 & 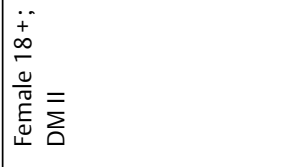 & 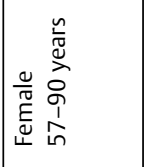 & 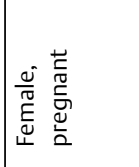 \\
\hline & & & & & 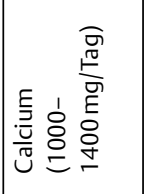 & 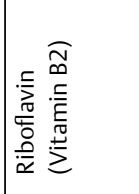 \\
\hline 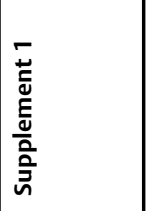 & 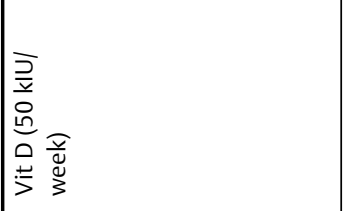 & 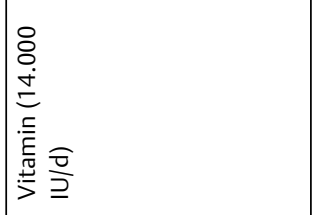 & 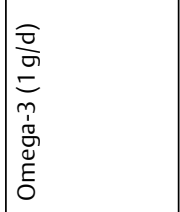 & 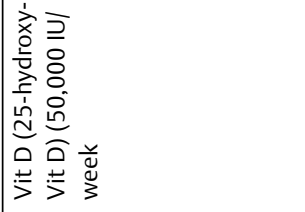 & 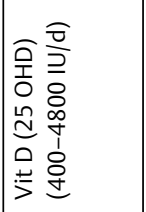 & 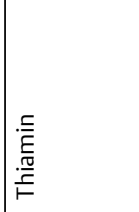 \\
\hline 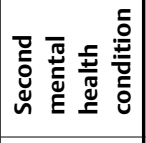 & 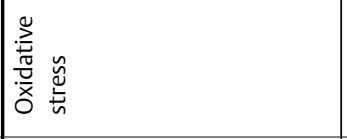 & 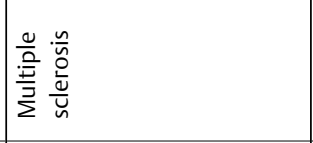 & & 离 & & 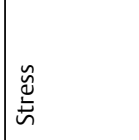 \\
\hline 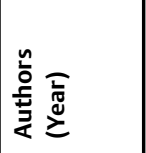 & 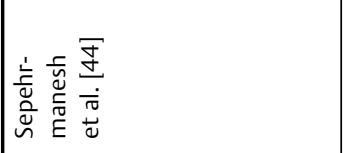 & 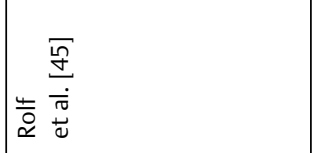 & 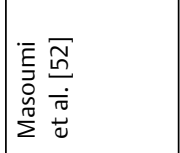 & 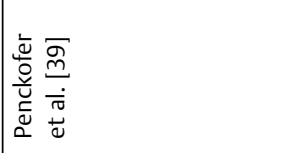 & 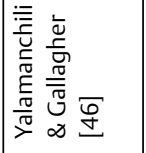 & 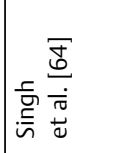 \\
\hline
\end{tabular}




\begin{tabular}{|c|c|c|c|c|}
\hline 密 & 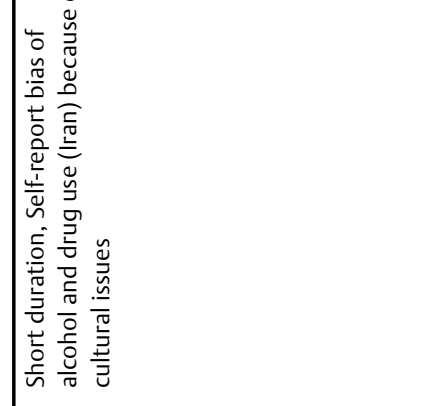 & 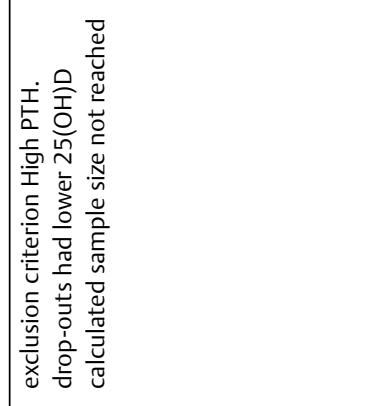 & & 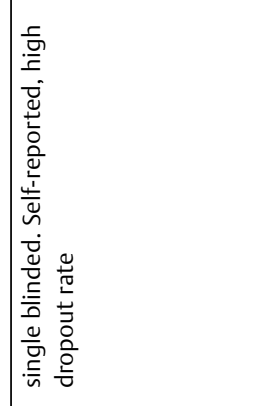 \\
\hline 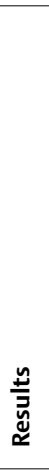 & 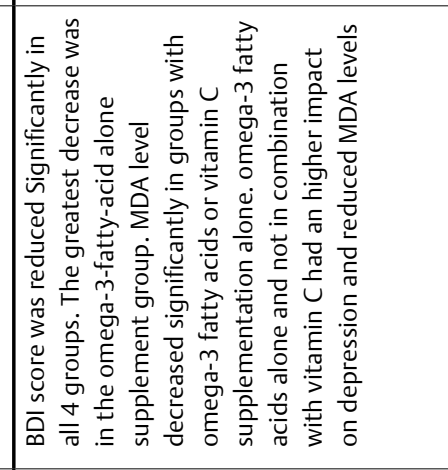 & 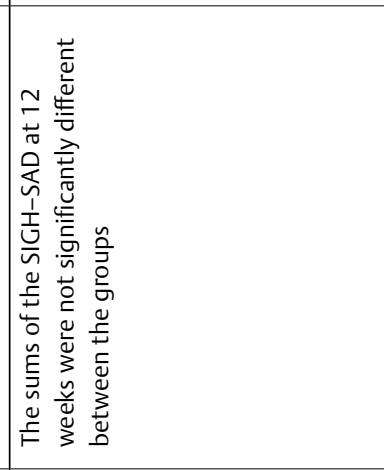 & 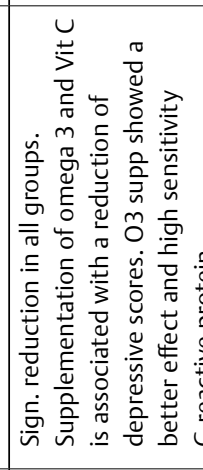 & 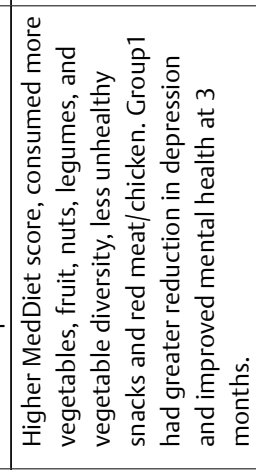 \\
\hline 䇏 & 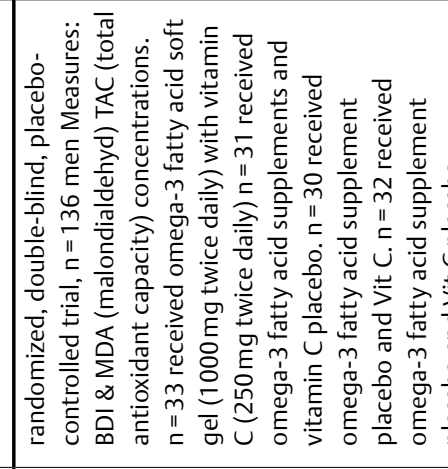 & 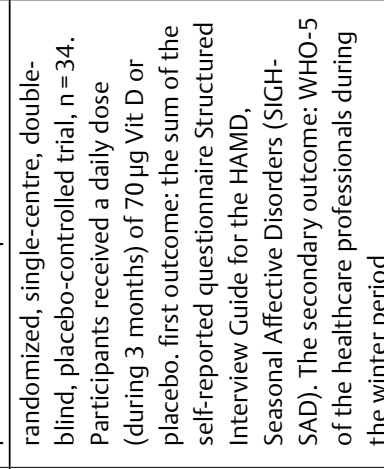 & 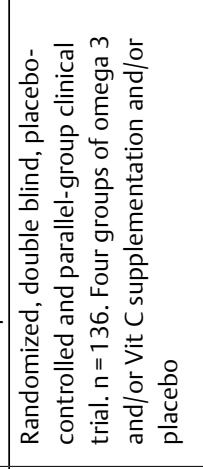 & 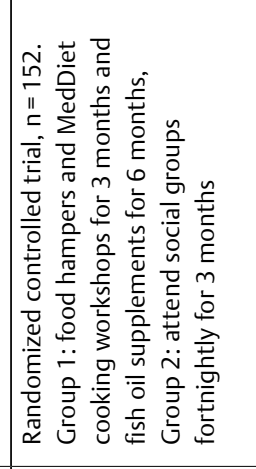 \\
\hline 党 & 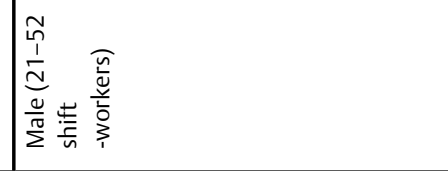 & 窸 & 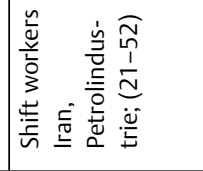 & \\
\hline$\overline{\underline{E}}$ & 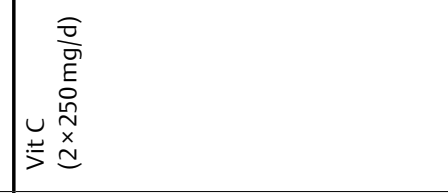 & & 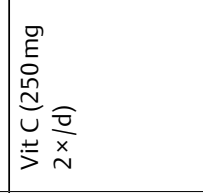 & $\mid$ \\
\hline & 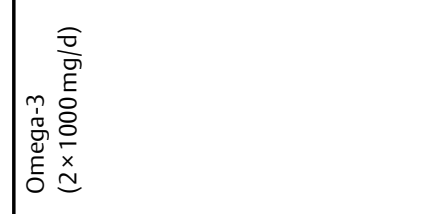 & 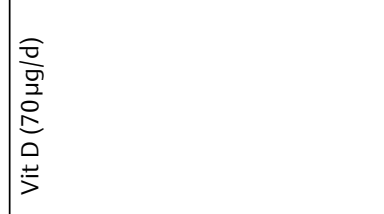 & 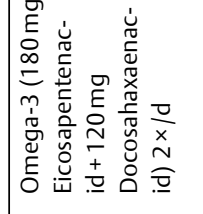 & 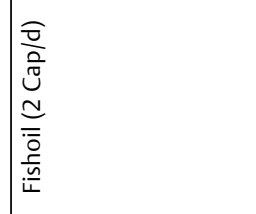 \\
\hline & & & & \\
\hline & 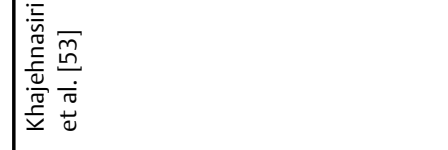 & 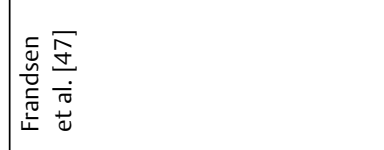 & 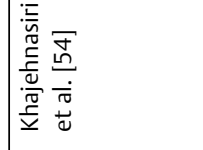 & 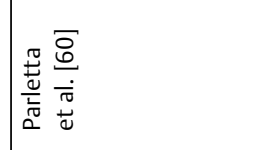 \\
\hline
\end{tabular}




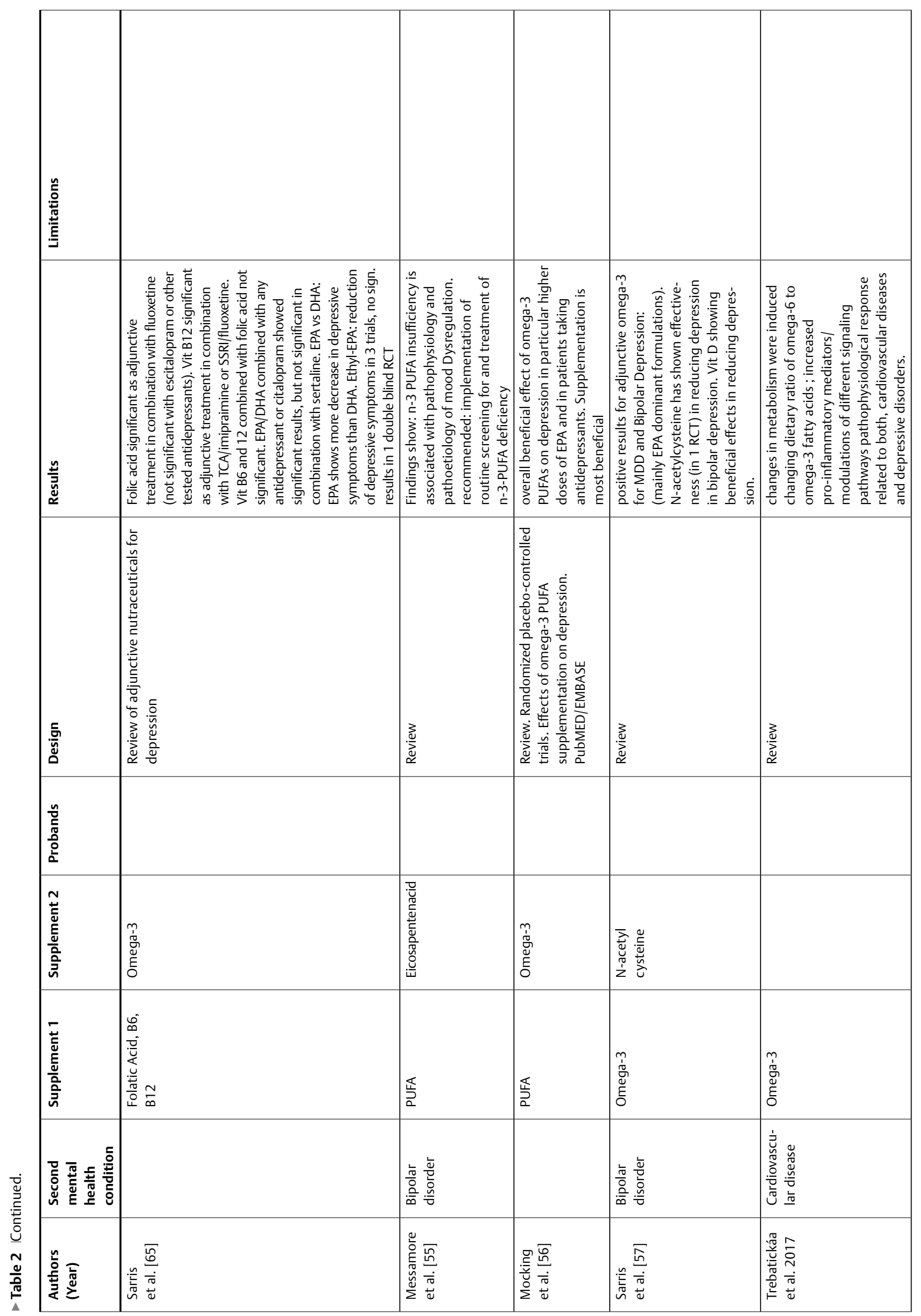




\begin{tabular}{|c|c|c|c|c|c|}
\hline & & 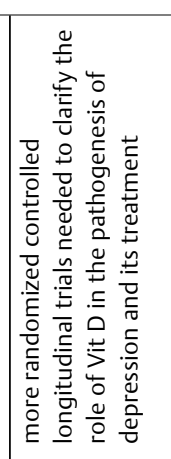 & & & \\
\hline 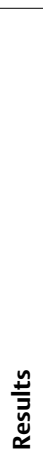 & 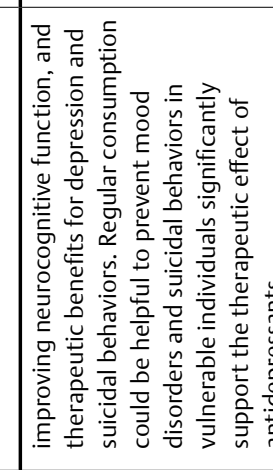 & 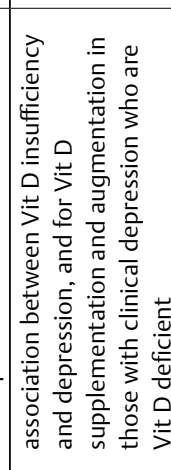 & 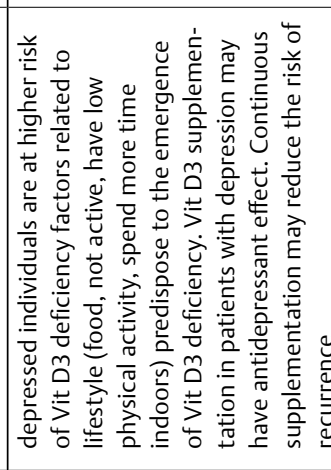 & 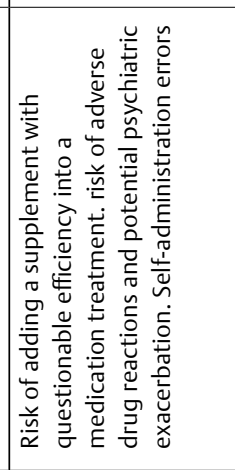 & 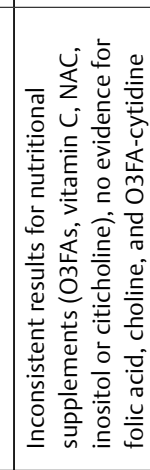 \\
\hline 总 & 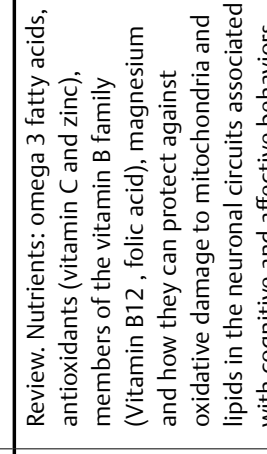 & 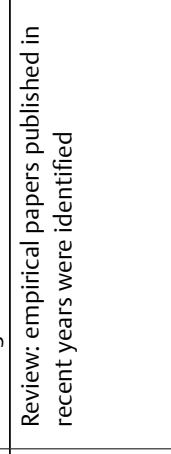 & 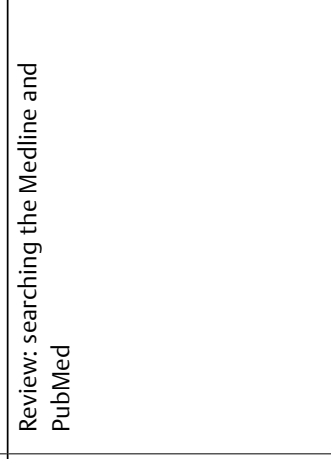 & 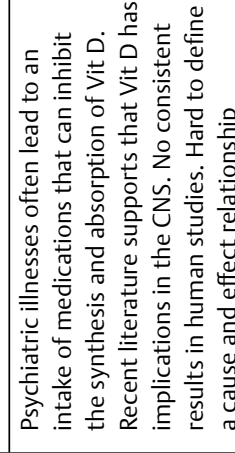 & 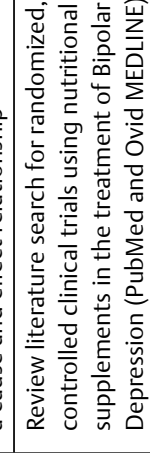 \\
\hline & & & & & \\
\hline $\bar{\Xi}$ & 誩 & & & $\frac{\underline{\underline{y}}}{\underline{\underline{z}}}$ & \\
\hline$\overline{\overline{\bar{\nu}}} \overline{\bar{n}}$ & 誉 & & $\left(\begin{array}{l}0 \\
\bar{z}\end{array}\right.$ & $\stackrel{p}{\lessgtr}$ & \\
\hline & & & & 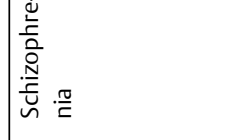 & \\
\hline & 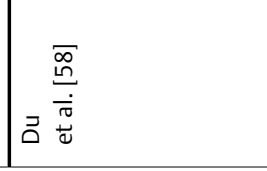 & 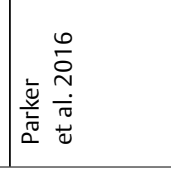 & 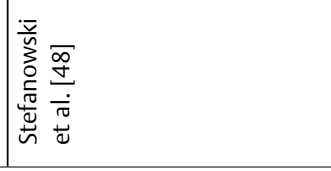 & 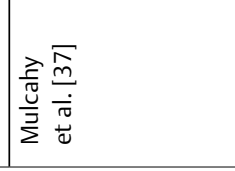 & 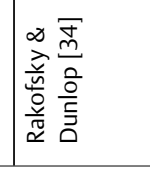 \\
\hline
\end{tabular}




\begin{tabular}{|c|c|c|c|c|c|}
\hline 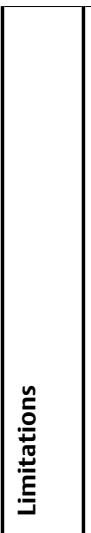 & 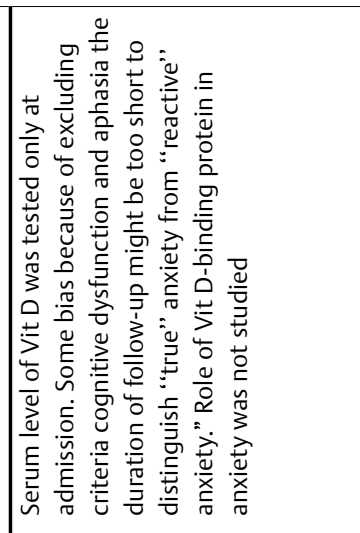 & 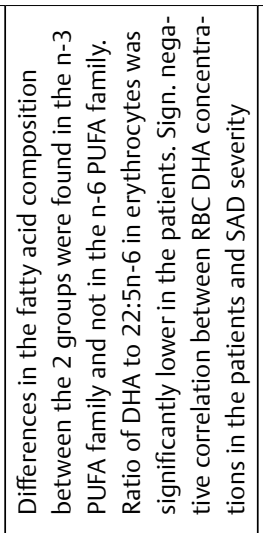 & & & 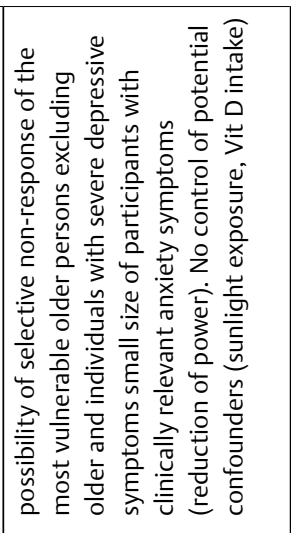 \\
\hline $\begin{array}{l}\stackrel{n}{\sharp} \\
\stackrel{\vec{y}}{\longleftarrow}\end{array}$ & 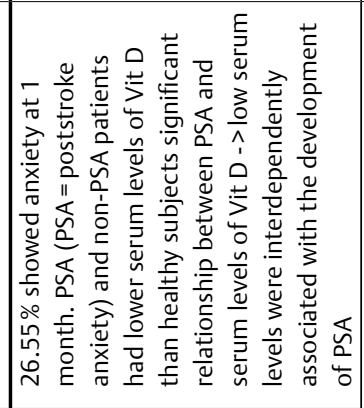 & 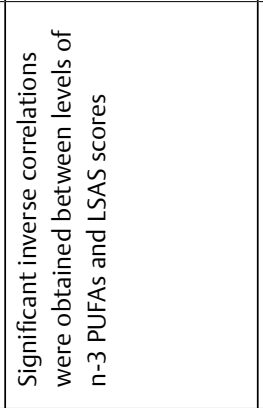 & 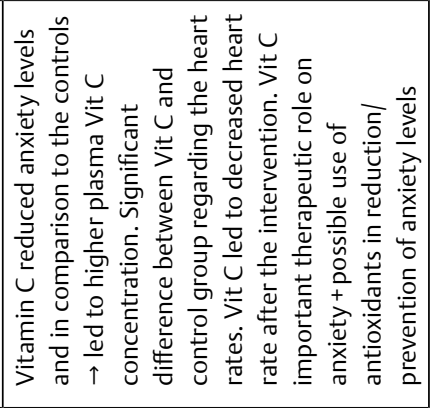 & 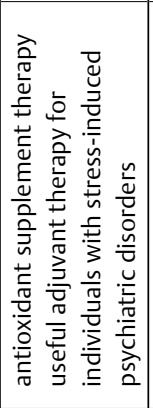 & 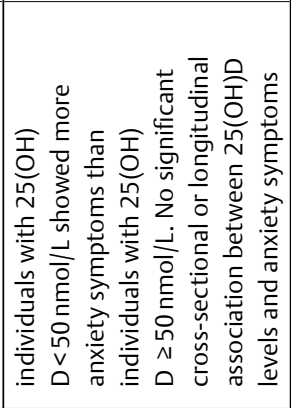 \\
\hline 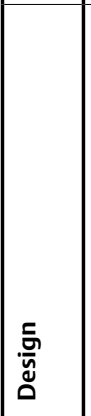 & 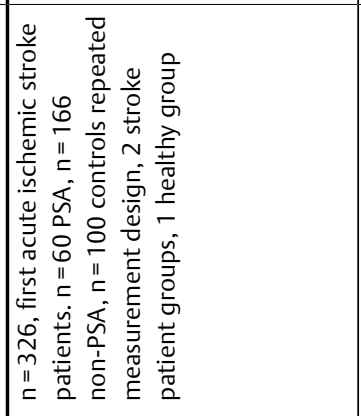 & 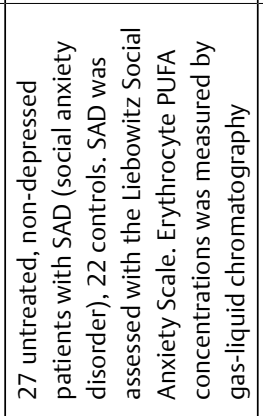 & 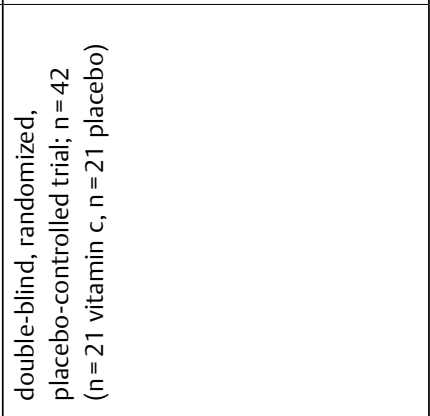 & 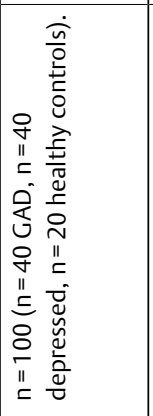 & 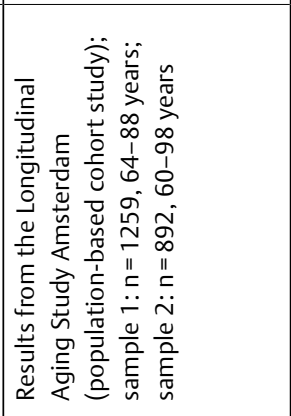 \\
\hline 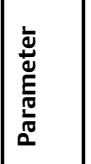 & $\stackrel{\circ}{\overrightarrow{>}}$ & 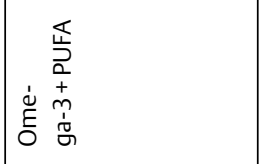 & & & $\stackrel{\circ}{\stackrel{2}{*}}$ \\
\hline 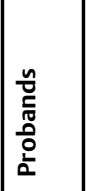 & 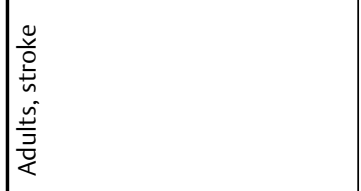 & $\frac{\frac{n}{5}}{\frac{3}{x}}$ & $\frac{\frac{n}{3}}{\frac{y}{2}}$ & 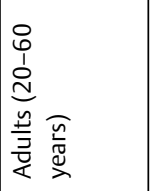 & 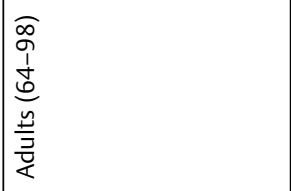 \\
\hline 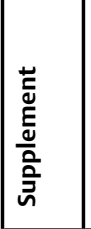 & & & 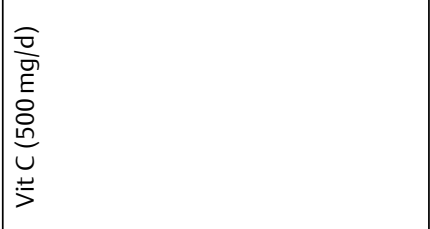 & 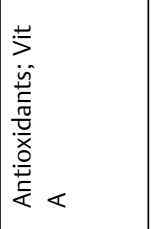 & \\
\hline 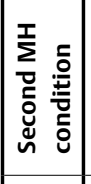 & & & & 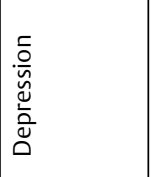 & \\
\hline 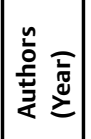 & 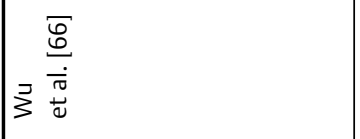 & 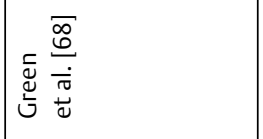 & 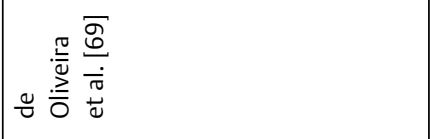 & 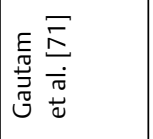 & 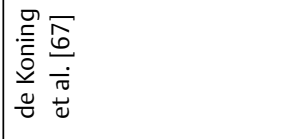 \\
\hline
\end{tabular}




\begin{tabular}{|c|c|c|c|c|}
\hline & 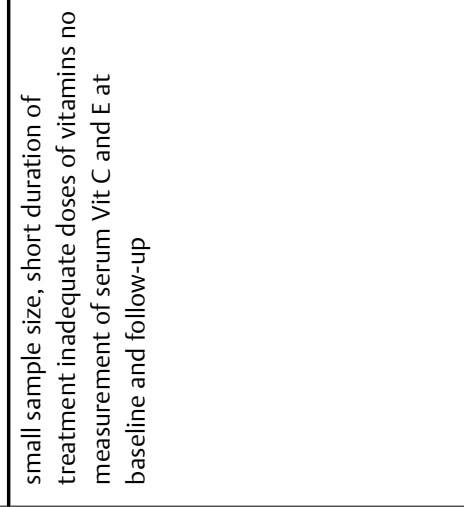 & 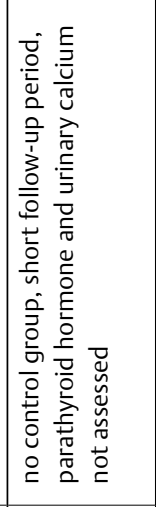 & & \\
\hline$\frac{\underline{y}}{\bar{z}}$ & 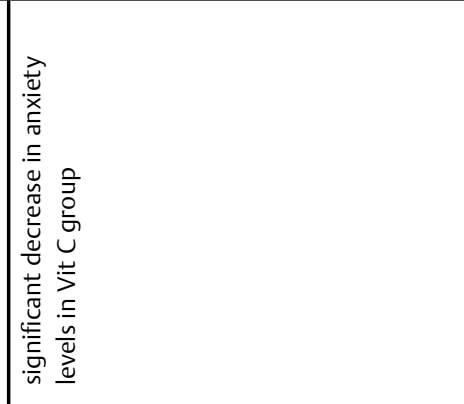 & 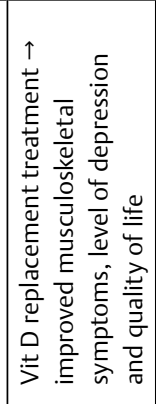 & 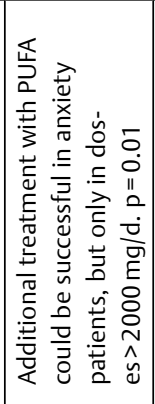 & 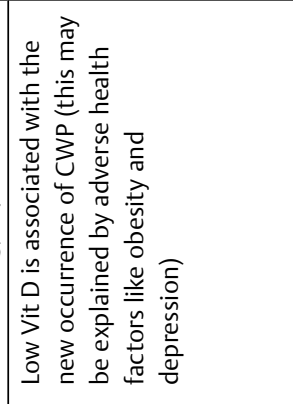 \\
\hline 点 & 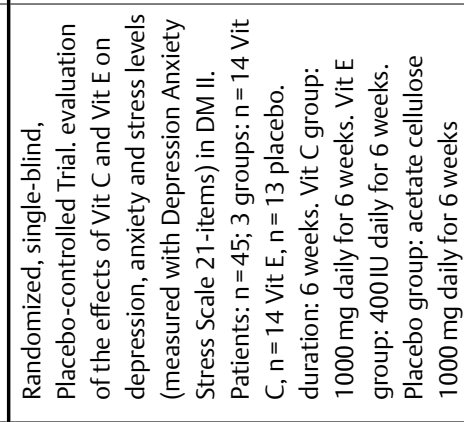 & 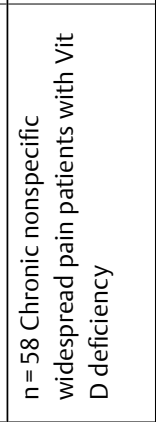 & 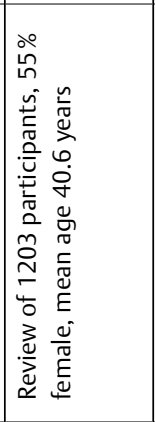 & 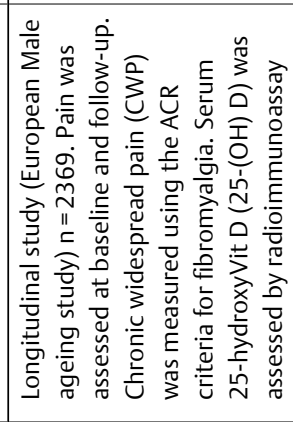 \\
\hline 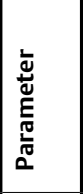 & & 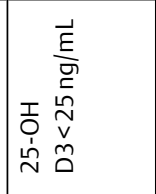 & & $\stackrel{0}{\risingdotseq}$ \\
\hline 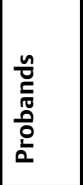 & 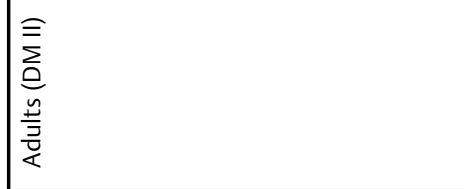 & & & 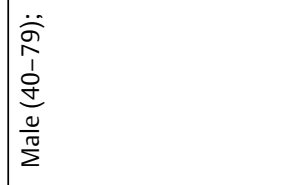 \\
\hline 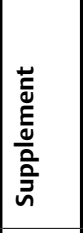 & 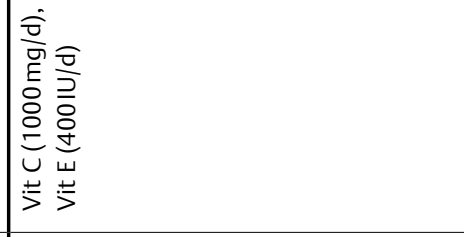 & 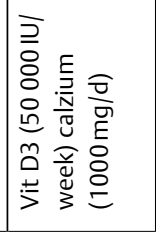 & 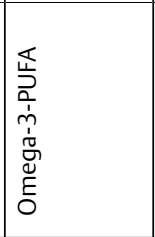 & 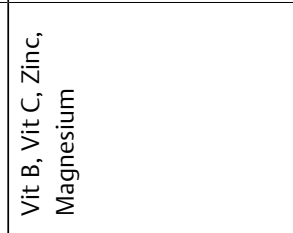 \\
\hline 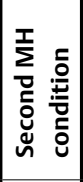 & 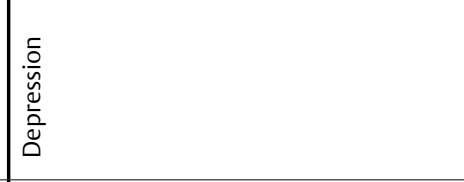 & 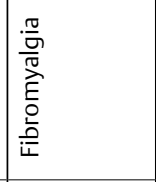 & & 要 \\
\hline 号 & 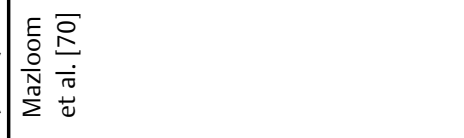 & 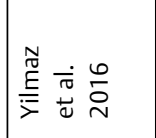 & 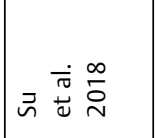 & 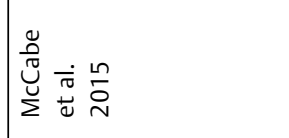 \\
\hline
\end{tabular}


20 patients receiving placebo, and there was no significant difference in outcomes; there was also no significant effect on inflammatory cytokines or CD8 + T cells [45]. A study of 274 females with low Vit $D$ levels receiving different doses of Vit $D$ and calcium showed no dose correlation [46]. A small survey with 34 nurses as probands also showed no effect of Vit D supplementation on depression [47]. Stefanowski et al. suggested that continuous supplementation may reduce the risk of recurrence of depression but saw only a possible effect in treatment [48].

Summarizing the described studies, there is no difference in relation to therapeutical effects when administrated Vit D [40-48].

\section{Other supplements}

The literature on other supplements was much poorer, mostly referring to PUFA. Smith et al. reported a $50 \%$ reduction in MAM-D scores under supplementation with docosahexanacid (DHA) over 8 weeks [49]. Kiecolt-Glaser et al. [50] undertook a placebo-controlled survey with 68 medical students (34 vs. 34) over 12 weeks; the findings showed a significant reduction in anxiety (BAI) but no changes in depressive symptoms (CES-D) [50]. A decrease in inflammatory agents, such as IL- 6 and TNF- $\alpha$, could be observed. The same authors [51] reported that a diet with high n-6:n-3 PUFA ratios is associated in the elderly with an elevated risk of depression and inflammatory diseases. Only trends regarding to depression could be seen in 60 females aged 45-65 in a triple blind design study of PUFA supplementation in combination with citalopram [52]. A placebo-controlled study on shift workers $(n=136)$ demonstrated reduced BDI scores in all groups, including placebo $[53,54]$. The PUFA group showed a stronger decline in inflammatory markers (C-reactive protein). Messarmore et al. [55] performed a review on PUFA in bipolar disorder and suggested a possible relationship with pathophysiology and pathoetiology [55]. Further reviews also displayed a positive effect on depression $[56,57]$. A review of patients with depression and PTSD found improvements in neurocognitive functioning and benefits for depressive symptoms and suicidality [58]. Trebatikáa et al. found a surplus for patients with comorbid cardiovascular disease and depression [59]. As a natural source of PUFA, fish oil, combined with a Mediterranean diet, also had a positive effect on depression [60]. Administration of supplements like DHA, PUFA, and fish oil showed a positive effect therapeutical approach, inflammatory factors, pathophysiology, and pathoetiology of depression [49-60].

The effect of Vit C ( $1 \mathrm{~g} /$ day) on depression, in combination with citalopram, was not superior to the effect of citalopram and a placebo [61]. Payne et al. reported that depressive persons had a lower intake of food containing Vit C [62]. Ngyuen et al. found reduced consumption of all vitamins except for Vit D and retinol in a sample of 1634 Japanese individuals and elevated depressive symptoms primarily in female and overweight participants [63]. The reduced intake of B-group vitamins, Vit K and Vit C may be a possible link to this symptomatology. Singh et al. reported the positive effect of thiamine on depression [64]. Sarris (2016) found that folic acid only had a positive effect in combination with fluoxetin, not with other tested antidepressive drugs; the effect of Vit B 12 on depression was significant in combination with imipramine and fluoxetin, Vit B 6 or a combination of the mentioned ones showed no effect [65]. This suggests that the administration of supplements in combina- tion with psychiatric medication lead to a positive effect on depression [62-64], but it has to kept in mind which combination and concentration can be inserted. [65].

\section{The role of supplements in anxiety}

The impact on anxiety is presented in $>$ Table 3.

The effects of Vit D on anxiety are also discussed very contradictorily. Wu et al. [66] reported the protective effects of higher Vit D levels in a cohort with anxiety and the history of stroke, whereas de Koning et al. [67] in another study could see no positive effect after adjustment for confounding variables. PUFA was reported to be useful [68] in anxiety, also the effect of Vit C [69-71].

\section{Discussion}

There are many indications of the complementary positive effects of Vit D and PUFA on depressive symptoms, anxiety, and pain, but there are few RCTs, and the recruitment of probands with mostly mild symptomatology and often relatively small number of probands recruited is a major limitation. The available reviews involve heterogeneous populations. Most authors recommend studies with more probands and narrower designs. Studies with more severely ill probands could only be carried out as an add-on to guideline therapies for ethical reasons. The supplements reviewed above are reported as harmless in most of the screened literature, in case that the authors are making a comment on this topic. Nevertheless, there is no clear objective and in case of overdose side effects and toxic symptoms could not generally be suspended, especially in case of the fat-soluble vitamins (A, E, D, K), which could accumulate in fatty tissue. However, in spite of the relatively low reported rate of such events, there are no remarkable reasons to suspend them generally as additions to standard therapy. The literature on supplements other than Vit D is scarce, so it is not possible to make recommendations. It has to be mentioned that most of the studies included were not designed to investigate the special therapeutical effect of supplements on psychiatric disorders, and for ethical reasons it is supposed to be critical to refuse evidence-based, guideline-suitable therapy to persons with severe illness for scientific reasons. Thus, for a final judgment of possible role of dietary supplements in depression and anxiety, further studies, especially designed to reveal such effects, are needed. Due to the fact that the topic of dietary supplement in psychiatry are not a special topic of research until now, and the psychiatric evidence of most of the screened literature is more a "side effect," the validity of our study is imitated. As per findings of previous reviews, the current evidence base is limited by investigations with low power, a lack of standardized experimental design with widely varying outcome measures, and an inhomogeneous patient population, limiting the generalizability of results. Many studies are also not primarily designed to evaluate the topics relevant to this paper, and information is gathered as a side effect of other research topics. Thus, to enhance knowledge on the effects of dietary supplements in depression and anxiety, further investigations and surveys, especially designed on these topics, has to be carried out. In our opinion, such surveys will be very valuable due to the relative low rate of contraindications for the use of such substances and the low rate 
of adverse effects, especially in comparison with standard pharmaceutical treatment.

\section{Limitations}

As a basic principle of a narrative review, the approach is vulnerable to limitations such as missed references, especially in comparison with a meta-analysis. We have tried our best to handle such limitations carefully. The aforementioned investigations do provide enough knowledge, however, to justify the efforts of a systematically and methodologically investigations with higher degree of evidence.

\section{Contributors}

$\mathrm{BE}$ and SK contributed to the literature search. $\mathrm{KH}$ wrote the first draft of the manuscript, and all authors contributed to and have approved the final manuscript.

\section{Conflict of Interest}

The authors all declare no conflicts of interest.

\section{References}

[1] Deutsche Gesellschaft für Ernährung. Press information: Bunte Pillen für's gute Gewissen - Was bringen Nahrungsergänzungsmittel? Bonn: 2012. Accessed at www.dge.de/uplaods/media/DGE-Pressemeldungenaktuell-09-2012-Brauchen-wir-NEM-JS.pdf Last accessed: July 10, 2018

[2] Nahrungsergänzungsmittel sind Verkaufsrenner. Dtsch Arztebl 2018 Accessed at www.aerzteblatt.de/ treffer mode $=$ s\& $w o=17 \&$ typ $=1 \&$ nid $=95718 \& s=$ nahrung serg\%E4nzungsmittel\&s = sind\&s = verkaufsrenner Last accessed: November 7, 2018

[3] Nahrungsergänzungsmitte: Deutsche setzen vor allem auf Magnesium. Dtsch Arztebl 2017 Accessed at www.aerzteblatt.de/treffer?mode $=s \&$ wo $=17 \&$ typ $=1 \&$ nid $=73518 \& \mathrm{~s}=$ allem $\& s=$ auf $\& s=$ deutsche $\& s=$ magn esium\&s = setzten\&s = vor Last accessed: November 7, 2018

[4] Haller C, Kearney T, Bent S et al. Dietary supplement adverse events: Report of one-year poison center surveillance project. J Med Tox 2008; 4: 84-92

[5] Rao N, Spiller HA, Hodges NL. An increase in dietary supplement exposure reported to US poison control centers. J Med Tox 2017; 13: 227-237

[6] Bjelakovic G, Dimitrinka N, Gluud LL et al. Antioxidant supplements for prevention of mortality in healthy participants and patients with various diseases. Cochrane Database Syst Rev 2012; 3: CD007176

[7] Belzeaux R, Boyer L, Ibrahim EC et al. Mood disorders are associated with a more severe hypovitaminosis D than schizophrenia. Psychiatry Res 2015; 229: 613-616

[8] Chu F, Ohinmaa A, Klarenbach S et al. Serum 25-hydroxyvitamin D concentrations and indicators of mental health: An analysis of the Canadian Health Measures Survey. Nutrients 2017; 9: E1116

[9] Collin C, Assmann KE, Deschasaux M et al. Plasma vitamin D status and recurrent depressive symptoms in the French SU.VI.MAX cohort. European J Nutr 2017; 56: 2289-2298

[10] Mizoue T, Kochi T, Akter S et al. Low serum 25-hydroxyvitamin D concentrations are associated with increased likelihood of having depressive symptoms among Japanese workers. J Nutr 2015; 145: 541-546
[11] von Känel R, Fardad N, Steurer N et al. Vitamin D deficiency and depressive symptomatology in psychiatric patients hospitalized with a current depressive episode: a factor analytic study. PLoS One 2015; 10: $1-15$

[12] Jovanova O, Aarts N, Noordam R et al. Vitamin D serum levels are cross-sectionally but not prospectively associated with late-life depression. Acta Psychiatr Scand 2017; 135: 185-194

[13] Jääskeläinen T, Knekt P, Suvisaari J et al. Higher serum 25-hydroxyvitamin $\mathrm{D}$ concentrations are related to a reduced risk of depression. $\mathrm{Br}$ J Nutr 2015; 113: 1418-1426

[14] Shin YC, Jung CH, Kim HJ et al. The associations among vitamin D deficiency, C-reactive protein, and depressive symptoms. J Psychosom Res 2016; 90: 98-104

[15] Thomas J, Al-Anouti F. Sun exposure and behavioral activation for hypovitaminosis D and depression: a controlled pilot study. Community Ment Health J 2018; 54: 860-865

[16] Parker GB, Brotchie H, Graham RK. Vitamin D and depression. J Affect Disord 2017; 208: 56-61

[17] von Känel R, Fardad N, Steurer N et al. Vitamin D deficiency and depressive symptomatology in psychiatric patients hospitalized with a current depressive episode: a factor analytic study. PLoS One 2015; 10: $1-15$

[18] Belzeaux R, Annweiler C, Bertrand JA et al. Association between hypovitaminosis $\mathrm{D}$ and cognitive inhibition impairment during major depression episode. J Affect Dis 2018; 225: 302-305

[19] Lee SH, Suh E, Park KC et al. Association of serum 25-hydroxyvitamin D and serum total cholesterol with depressive symptoms in Korean adults: the Fifth Korean National Health and Nutrition Examination Survey (KNHANES V, 2010-2012). Public Health Nutrition 2017; 20: 1836-1843

[20] Brouwer-Brolsma EM, Dhonukshe-Rutten RAM, van Wijngaarden JP et al. Low vitamin $D$ status is associated with more depressive symptoms in Dutch older adults. Eur J Nutr 2016; 55: 1525-1534

[21] Accortt EE, Dunkel Schetter C, Peters RM et al. Lower prenatal vitamin D status and postpartum depressive symptomatology in African American women: Preliminary evidence for moderation by inflammatory cytokines. Arch Womens Ment Health 2016; 19: 373-383

[22] Johansson P, Alehagen U, van der Wal MH et al. Vitamin D levels and depressive symptoms in patients with chronic heart failure. Int J Cardiol 2016; 207: 185-189

[23] Kim SH, Seok H, Kim DS. Relationship between serum vitamin D levels and symptoms of depression in stroke patients. Ann Rehabil Med 2016; 40: 120-125

[24] Rabenberg M, Harisch C, Rieckmann N et al. Association between vitamin $\mathrm{D}$ and depressive symptoms varies by season: results from the German Health Interview and Examination Survey for Adults (DEGS1). J Affect Disord 2016; 204: 92-98

[25] Kerr DC, Zava DT, Piper WT et al. Associations between vitamin D levels and depressive symptoms in healthy young adult women. Psychiatry Res 2015; 227: 46-51

[26] Elstgeest LE, de Koning EJ, Brouwer IA et al. Change in serum 25-hydroxyvitamin $\mathrm{D}$ and parallel change in depressive symptoms in Dutch older adults. Eur J Endocrinol 2018; 179: 239-249

[27] Can MS, Baykan H, Erensoy $\mathrm{N}$ et al. Vitamin d levels and vitamin D receptor gene polymorphism in major depression. Psychiatrica Danubia 2017; 29: 179-185

[28] Almeida OP, Hankey G], Yeap BB et al. Vitamin D concentration and its association with past, current and future depression in older men: the Health in Men Study. Maturitas 2015; 81: 36-41

[29] Callegari ET, Reavley N, Gorelik A et al. Serum 25-hydroxyvitamin D and mental health in young Australian women: results from the Safe-D study. J Affect Disord 2017; 224: 48-55 
[30] van den Berg KS, Marijnissen RM, van den Brink RH et al. Vitamin D deficiency, depression course and mortality: longitudinal results from the Netherlands Study on Depression in Older Persons (NESDO). J Psychosom Res 2016; 83: 50-56

[31] Dana-Alamdari L, Kheirouri S, Noorazar SG. Serum 25-hydroxyvitamin D in patients with major depressive disorder. Iran J Public Health 2015; 44: 690-697

[32] Liu J], Galfalvy HC, Cooper TB et al. Omega-3 polyunsaturated fatty acid (PUFA) status in major depressive disorder with comorbid anxiety disorders. J Clin Psychiatry 2013; 74: 732-738

[33] Otoki Y, Hennebelle M, Levitt AJ et al. Plasma phosphatidylethanolamine and triacylglycerol fatty acid concentrations are altered in major depressive disorder patients with seasonal pattern. Lipids 2017; 52: 559-571

[34] Rakofsky J], Dunlop BW. Review of nutritional supplements for the treatment of bipolar depression. Depress Anxiety 2014; 31: 379-390

[35] Hashimoto $\mathrm{K}$, Ishima T, Sato $\mathrm{Y}$ et al. Increased levels of ascorbic acid in the cerebrospinal fluid of cognitively intact elderly patients with major depression: a preliminary study. Sci Rep 2017; 3485: 1-7

[36] Payne ME, Steck SE, George RR et al. Fruit, vegetable, and antioxidant intakes are lower in older adults with depression. J Acad Nutr Diet 2012; 112: 2022-2027

[37] Mulcahy K, Trigoboff E, Opler L et al. Physician prescribing practices of vitamin D in a psychiatric hospital. Innov Clin Neurosci 2016; 13: $21-27$

[38] Stokes CS, Grünhage F, Baus C et al. Vitamin D supplementation reduces depressive symptoms in patients with chronic liver disease. Clin Nutr 2016; 35: 950-957

[39] Penckofer S, Byrn M, Adams W et al. Vitamin D supplementation improves mood in women with type 2 diabetes. J Diabetes Res 2017; 2017: 8232863

[40] Gowda U, Mutowo MP, Smith B] et al. Vitamin D supplementation to reduce depression in adults: Meta-analysis of randomized controlled trials. Nutrition 2015; 31: 421-429

[41] Mousa A, Naderpoor N, de Courten MP et al. Vitamin D and symptoms of depression in overweight or obese adults: a cross-sectional study and randomized placebo-controlled trial. J Steroid Biochem Mol Biol 2018; 177: 200-208

[42] Marsh WK, Penny JL, Rothschild AJ. Vitamin D supplementation in bipolar depression: a double blind placebo controlled trial. J Psychiatr Res 2017; 95: 48-53

[43] Kjærgaard M, Waterloo K, Wang CE et al. Effect of vitamin D supplement on depression scores in people with low levels of serum 25-hydroxyvitamin D: nested case-control study and randomised clinical trial. Br J Psychiatry 2012; 201: 360-368

[44] Sepehrmanesh Z, Kolahdooz F, Abedi F et al. Vitamin D supplementation affects the Beck Depression Inventory, insulin resistance, and biomarkers of oxidative stress in patients with major depressive disorder: a randomized, controlled clinical trial. J Nutr 2016; 146: 243-248

[45] Rolf L, Muris AH, Bol Y et al. Vitamin D3 supplementation in multiple sclerosis: Symptoms and biomarkers of depression. J Neurol Sci 2017; 378: $30-35$

[46] Yalamanchili V, Gallagher JC. Dose ranging effects of vitamin D3 on the geriatric depression score: a clinical trial. J Steroid Biochem Mol Biol 2018; 178: 60-64

[47] Frandsen TB, Pareek M, Hansen JP et al. Vitamin D supplementation for treatment of seasonal affective symptoms in healthcare professionals: A double-blind randomised placebo-controlled trial. BMC Res Notes 2014; 528: 1-8

[48] Stefanowski B, Antosik-Wójcińska AZ, Święcicki Ł. Wpływ niedoboru witaminy D3 na poziom nasilenia objawów depresyjnych. Przegląd aktualnych badań. Psychiatr Pol 2017; 51: 437-454
[49] Smith D], Sarris ], Dowling N et al. Adjunctive low-dose docosahexaenoic acid (DHA) for major depression: an open-label pilot trial. Nutr Neurosci 2018; 21: 224-228

[50] Kiecolt-Glaser JK, Belury MA, Andridge R et al. Omega-3 supplementation lowers inflammation and anxiety in medical students: a randomized controlled trial. Brain Behav Immun 2011; 25: 1725-1734

[51] Kiecolt-Glaser JK, Belury MA, Porter K et al. Depressive symptoms, n-6:n-3 fatty acids, and inflammation in older adults. Psychosom Med 2007; 69: 217-224

[52] Masoumi SZ, Kazemi F, Tavakolian S et al. Effect of Citalopram in combination with omega-3 on depression in post-menopausal women: A triple blind randomized controlled trial. J Clin Diagn Res 2016; 10: 1-5

[53] Khajehnasiri F, Akhondzadeh S, Mortazavi SB et al. Are supplementation of omega- 3 and ascorbic acid effective in reducing oxidative stress and depression among depressed shift workers? Int J Vitam Nutr Res 2015; 85: 299-310

[54] Khajehnasiri F, Mortazavi SB, Allameh A et al. Effect of omega-3 and ascorbic acid on inflammation markers in depressed shift workers in Shahid Tomdgoyan Oil Refinery, Iran: A randomized double-blind placebo-controlled study. J Clin Biochem Nutr 2013; 53: 36-40

[55] Messamore E, Almeida DM, Jandacek RJ et al. Polyunsaturated fatty acids and recurrent mood disorders: phenomenology, mechanisms, and clinical application. Prog Lipid Res 2017; 66: 1-13

[56] Mocking R], Harmsen I, Assies ] et al. Meta-analysis and meta-regression of omega-3 polyunsaturated fatty acid supplementation for major depressive disorder. Transl Psychiatry 2016; 6: 1-6

[57] Sarris J. Clinical use of nutraceuticals in the adjunctive treatment of depression in mood disorders. Austral Psychiatry 2017; 25: 369-372

[58] Du J, Zhu M, Bao H et al. The role of nutrients in protecting mitochondrial function and neurotransmitter signaling: Implications for the treatment of depression, PTSD, and suicidal behaviours. Crit Rev Food Sci Nutr 2016; 56: 2560-2578

[59] Trebatická J, Dukát A, Ďuračková Z et al. Cardiovascular diseases, depression disorders and potential effects of omega- 3 fatty acids. Physiol Res 2017; 66: 363-382

[60] Parletta N, Zarnowiecki D, Cho J et al. A Mediterranean-style dietary intervention supplemented with fish oil improves diet quality and mental health in people with depression: a randomized controlled trial (HELFIMED). Nutr Neurosci 2017; 22: 474-487

[61] Sahraian A, Ghanizadeh A, Kazemeini F. Vitamin C as an adjuvant for treating major depressive disorder and suicidal behaviour, a randomized placebo-controlled clinical trial. Trials 2015; 94: 1-8

[62] Payne ME, Steck SE, George RR et al. Fruit, vegetable, and antioxidant intakes are lower in older adults with depression. J Acad Nutr Diet 2012; 112: 2022-2027

[63] Nguyen TT, Tsujiguchi H, Kambayashi Y et al. Relationship between vitamin intake and depressive symptoms in elderly Japanese individuals: differences with gender and body mass index. Nutrients 2017; 1319: 1-16

[64] Singh A, Trumpff C, Genkinger ] et al. Micronutrient dietary intake in Latina pregnant adolescents and its association with level of depression, stress, and social support. Nutrients 2017; 1212: 1-16

[65] Sarris J, Murphy J, Mischoulon D et al. Adjunctive nutraceuticals for depression: a systematic review and meta-analyses. Am J Psychiatry 2016; 173: 575-587

[66] Wu C, Ren W, Cheng J et al. Association between serum levels of vitamin $\mathrm{D}$ and the risk of post-stroke anxiety. Medicine (Baltimore) 2016; 95: 1-5 
[67] de Koning E], Verweij L, Lips P et al. The relationship between serum 25(OH)D levels and anxiety symptoms in older persons: Results from the Longitudinal Aging Study Amsterdam. J Psychosom Res 2017; 97: 90-95

[68] Green P, Hermesh H, Monselise A et al. Red cell membrane omega-3 fatty acids are decreased in nondepressed patients with social anxiety disorder. Eur Neuropsychopharmacol 2006; 16: 107-113

[69] de Oliveira I], de Souza VV, Motta V et al. Effects of oral vitamin C supplementation on anxiety in students: a double-blind, randomized, placebo-controlled trial. Pak J Biol Sci 2015; 18: 11-18
[70] Mazloom Z, Ekramzadeh M, Hejazi N. Efficacy of supplementary vitamins $C$ and $E$ on anxiety, depression and stress in type- 2 diabetic patients: a randomized, single-blind, placebo-controlled trial. Pak J Biol Sci 2013; 1-4

[71] Gautam M, Agrawal M, Gautam M et al. Role of antioxidants in generalised anxiety disorder and depression. Indian J Psychiatry 2012; 54: $244-247$ 